\title{
Explication of the Potential of
} 2-Hydroxy-4-Methoxybenzaldehyde in Hampering Uropathogenic Proteus mirabilis Crystalline Biofilm and Virulence

\begin{abstract}
Ravindran Durgadevi', Gurusamy Abirami', Rajaiah Alexpandi ${ }^{1}$, Kumar Nandhini', Ponnuchamy Kumar ${ }^{2}$, Santhiyagu Prakash ${ }^{3}$ and Arumugam Veera Ravi ${ }^{*}$
\end{abstract}

${ }^{1}$ Department of Biotechnology, Alagappa University, Karaikudi, India, ${ }^{2}$ Food Chemistry and Molecular Cancer Biology Lab, Department of Animal Health and Management, Alagappa University, Karaikudi, India, ${ }^{3}$ Department of Basic Science, Tamilnadu Dr. J. Jayalalithaa Fisheries University, Chennai, India

Proteus mirabilis is an important etiological agent of catheter-associated urinary tract infections (CAUTIS) owing to its efficient crystalline biofilm formation and virulence enzyme production. Hence, the present study explicated the antibiofilm and antivirulence efficacies of 2-hydroxy-4-methoxybenzaldehyde $(\mathrm{HMB})$ against $P$. mirabilis in a non-bactericidal manner. HMB showed concentration-dependent biofilm inhibition, which was also evinced in light, confocal, and scanning electron microscopic (SEM) analyses. The other virulence factors such as urease, hemolysin, siderophores, and extracellular polymeric substances production as well as swimming and swarming motility were also inhibited by $\mathrm{HMB}$ treatment. Further, $\mathrm{HMB}$ treatment effectively reduced the struvite/apatite production as well as crystalline biofilm formation by $P$. mirabilis. Furthermore, the results of gene expression analysis unveiled the ability of $\mathrm{HMB}$ to impair the expression level of virulence genes such as $f l h B, f l h D, r s b A$, $s p e A$, ureR, $h p m A$, and $h p m B$, which was found to be in correlation with the results of in vitro bioassays. Additionally, the cytotoxicity analysis divulged the innocuous characteristic of $\mathrm{HMB}$ against human embryonic kidney cells. Thus, the present study reports the potency of $\mathrm{HMB}$ to act as a promising therapeutic remedy for P. mirabilis-instigated CAUTIs.

Keywords: 2-hydroxy-4-methoxybenzaldehyde, antivirulence, biofilm inhibition, crystalline biofilm, Proteus mirabilis

\section{INTRODUCTION}

Urinary tract infections (UTIs) are the most prevalent bacterial infections acquired in health-care settings that can affect any part of urinary system including the kidneys, bladder, ureters, and urethra (Stamm and Norrby, 2001). Among the hospital-acquired UTIs, $70-80 \%$ are associated with the urinary catheter, which is a urine drainage tube inserted into the bladder through the urethra. The prolonged usage of indwelling urinary catheters is the most crucial risk factor for triggering complicated CAUTIs (Trautner, 2010). Bacterial pathogens are major contributors of complicated UTIs owing to their virulence secretion and biofilm formation on catheter surfaces (Soto, 2014; Flores-Mireles et al., 2015). 
In this midst, Proteus mirabilis is an imperious etiological agent of CAUTIs in patients undertaking long-term catheterization (Jacobsen et al., 2008).

Proteus mirabilis, a species of Morganellaceae family, is well known for its bulls'-eye-pattern swarming motility and urease activity (Schaffer and Pearson, 2015; Adeolu et al., 2016; Hamilton et al., 2018). The production of virulence factors aids in promoting the adhesion and biofilm formation of $P$. mirabilis on biological as well as abiotic urinary catheter surfaces (Hola et al., 2012). Owing to the flagella-mediated motility, P. mirabilis can easily transmit the infection to the urinary bladder through the urethra and to other parts of the host system through the bloodstream. During swarming, P. mirabilis co-regulates the expression of flagellar gene hierarchy as well as virulence genes (Belas and Suvanasuthi, 2005) encoding hemolysin HpmA and urease enzymes (Fraser et al., 2002; Morgenstein et al., 2010). These virulence factors are responsible for the complications of $P$. mirabilis infections including urolithiasis, bacteremia, and sepsis (Foxman and Brown, 2003).

Also, $P$. mirabilis has the ability to form crystalline biofilm under urinary environment, which happens as a sequel of alkalization of urine by the enzyme urease that catalyzes the hydrolysis of urea in urine and produces ammonia. Consequently, the production of ammonia leads to the precipitation of calcium and magnesium ions and formation of urinary stones composed of magnesium ammonium phosphate (struvite) and calcium phosphate (apatite). These precipitated minerals entrap within the $P$. mirabilis biofilm matrix formed on the urinary catheter, thus forming a dense crystalline biofilm and eventually blocking the urine flow through the catheter (Holling et al., 2014; Torzewska and Rozalski, 2014).

Moreover, the biofilm formation aids in protecting the pathogen from host defense mechanisms and boosts its resistance against antimicrobial drugs (Armbruster et al., 2018; Prywer et al., 2018). The sustained development of drug resistance in $P$. mirabilis sets up a severe menace in clinical settings. Therefore, prevention and appropriate treatment strategies are of utmost necessity. Research on plant resource-based traditional therapies has been tremendously increased worldwide for controlling human infectious diseases. In parallel, antibiofilm and antivirulence strategies have become an effective method to combat antimicrobial resistance (Cheng, 2016; Raorane et al., 2019). Inactivation of virulence secretion by targeting the transcriptional gene regulatory system will disarm the pathogens rather than killing or inhibiting their growth and will render them susceptible to natural host defenses. With due recognition of the global transcriptional regulator of virulence factor expression in bacterial pathogenicity, targeting such mechanism would be a precise way to control the bacterial infections (Jiang et al., 2019). As bactericidal activity of antibiotics exerts selection pressure on bacterial population, selective mutations are created in the population that allows the bacteria to escape drug activity (Totsika, 2017). Therefore, inhibition of virulence factors presents an attractive alternative to antibiotics. The virulence inhibitors may interfere with quorum signaling molecule, which regulates the expression of virulence factors and, thereby, abolishes bacterial pathogenicity (Yang et al., 2012).
Several prior studies have reported the proficient antibiofilm and antipathogenic properties of medicinal plants and their bioactive compounds against various clinically relevant bacterial pathogens (Harjai et al., 2010; Torzewska and Rozalski, 2014; Ramanathan et al., 2018; Alexpandi et al., 2019). Among the identified phytocompounds, 2-hydroxy-4-methoxybenzaldehyde (HMB), which is majorly present in the roots of traditional Indian plant, Hemidesmus indicus, has drawn the attention of researchers owing to its numerous biological properties (Wang et al., 2010; Srikanta et al., 2011; Kannappan et al., 2019). Although several previous reports have demonstrated the pharmacological activities of HMB, none of the studies have described its antibiofilm and antivirulence efficacies against Gram-negative bacterial pathogens. In light of the aforesaid facts, the present study unwinds the antibiofilm and antivirulence potential of $\mathrm{HMB}$ against the exclusive uropathogen, $P$. mirabilis.

\section{MATERIALS AND METHODS}

\section{Ethics Statement}

In this study, blood samples were collected from healthy human volunteers by a trained technical person for blood survivability assay. The usage of human blood sample and experimental procedure was assessed and approved by the Institutional Ethical Committee, Alagappa University, under no. IEC/AU/2018/6.

\section{Bacterial Strain and Culture Condition}

Proteus mirabilis reference strain (American Type Culture Collection [ATCC] 7002) and clinical isolate (CI) (GenBank accession no. MG905628) were used in this study. Both the strains were maintained in Luria-Bertani (LB; HiMedia, Mumbai) ( $\mathrm{pH}$ $7.2 \pm 0.2$ ) agar plate and cultivated in LB broth at $120 \mathrm{rpm}$ in a shaker overnight at $37^{\circ} \mathrm{C}$. For experimental purpose, the overnight culture was subcultured in fresh LB broth until it reached $0.4 \mathrm{OD}$ at $600 \mathrm{~nm}\left(10^{8} \mathrm{CFU} / \mathrm{ml}\right)$.

\section{2-Hydroxy-4-Methoxybenzaldehyde}

2-Hydroxy-4-methoxybenzaldehyde was purchased from SigmaAldrich (St. Louis, MO, United States). For experimental purpose, a stock solution of $50 \mathrm{mg} / \mathrm{ml}$ concentration of $\mathrm{HMB}$ was prepared using methanol.

\section{Determination of Minimum Inhibitory Concentration and Minimum Biofilm Inhibitory Concentration}

The effect of $\mathrm{HMB}$ on $P$. mirabilis growth and biofilm formation was assessed by microbroth dilution method as described by Clinical and Laboratory Standards Institute [CLSI], 2016. Briefly, $1 \%$ of $P$. mirabilis $\left(10^{8} \mathrm{CFU} / \mathrm{ml}\right)$ culture was added to LB media $(1 \mathrm{ml})$ supplemented with increasing concentrations of HMB $(25-400 \mu \mathrm{g} / \mathrm{ml})$ and incubated at $37^{\circ} \mathrm{C}$ for $24 \mathrm{~h}$. LB containing $0.8 \%$ of methanol and $1 \%$ of culture was considered as negative control. After incubation, the growth inhibition was measured at $\mathrm{OD}_{600} \mathrm{~nm}$ using UV-Vis Spectrophotometer (U2800, Hitachi, Japan). Minimum inhibitory concentration (MIC) 
was determined at the concentration of HMB that yields complete visible growth inhibition. Afterward, the planktonic cells were removed from both HMB-treated and untreated $P$. mirabilis samples, and the biofilm biomass was quantified by crystal violet (CV) staining method (Musthafa et al., 2010). The percentage of biofilm biomass inhibition was calculated using the following equation:\% of Inhibition $=\left(\left[\right.\right.$ Control $\mathrm{OD}_{570} \mathrm{~nm}-$ Treated $\left.\mathrm{OD}_{570 \mathrm{~nm}}\right] /$ Control $\left.\mathrm{OD}_{570 \mathrm{~nm}}\right) \times 100$.

\section{Assessment of Cellular Viability Using 2,3-Bis(2-Methoxy-4-Nitro-5- Sulfophenyl)-2H-Tetrazolium-5- Carboxanilide Assay}

The cellular activity of $P$. mirabilis under $\mathrm{HMB}$ treatment was measured by XTT [2,3-bis(2-methoxy-4-nitro-5-sulfophenyl)$2 \mathrm{H}$-tetrazolium-5-carboxanilide] reduction assay. In the presence of an electron-coupling reagent (menadione), the cleavage of tetrazolium salt XTT produces a strongly colored soluble formazan salt through a complex cellular mechanism of metabolically active cells (Stockert et al., 2018). In the present study, the HMB-treated and untreated $P$. mirabilis cells were incubated with the XTT-menadione mixture [50 $\mu \mathrm{l}$ of XTT (Sigma); $4 \mu \mathrm{l}$ of menadione (HiMedia, Mumbai)] for $1 \mathrm{~h}$ at $37^{\circ} \mathrm{C}$ in the dark. Following incubation, the absorbance of formazan dye formed in the cell-free supernatants was measured at $\mathrm{OD}_{470 \mathrm{~nm}}$, which directly correlates to the number of viable cells in the culture (Singh et al., 2011).

\section{Microscopic Analysis}

Proteus mirabilis was allowed to form biofilm on the surface of glass slides $(1 \times 1 \mathrm{~cm})$ in the absence and presence of HMB [minimum biofilm inhibitory concentration (MBIC)] and incubated at $37^{\circ} \mathrm{C}$ for $24 \mathrm{~h}$. After incubation, the slides were rinsed with distilled water and dried in air. Then the slides were stained using $0.4 \% \mathrm{CV}$ or $0.1 \%$ acridine orange (AO) for light microscopic (LM) (Nikon Eclipse 80i, Shinagawa-ku, Japan) and confocal laser scanning microscopic (CLSM) (Zeiss LSM 710, Germany) analyses, respectively.

For SEM analysis, HMB-treated and untreated biofilm cells that formed on the glass slides were fixed using glutaraldehyde $(2.5 \%)$ at $4^{\circ} \mathrm{C}$ for $2 \mathrm{~h}$. Then the slides were gradually dehydrated using increasing concentrations (20, 40, 60, 80, and 100\%) of ethanol. After that, the gold prior sputter coating was implemented in the slides to be observed under the field-emission SEM (FESEM) (Quanta FEG 200).

\section{Effect of 2-Hydroxy-4- Methoxybenzaldehyde on Proteus mirabilis Exopolysaccharide Production Exopolysaccharide Extraction and Quantification}

The cell-free and cell-bound exopolysaccharides (EPSs) were extracted from HMB-treated and untreated P. mirabilis samples as described by Sivasankar et al. (2016) with minor modifications. Briefly, P. mirabilis cells were grown at $37^{\circ} \mathrm{C}$ for $24 \mathrm{~h}$ in
LB media supplemented with and without HMB (MBIC). After incubation, the cell-free culture supernatant (CFCS) was collected from both HMB-treated and untreated samples by centrifugation at $8,000 \mathrm{rpm}$ for $10 \mathrm{~min}$. Subsequently, the cell pellets were suspended in freshly prepared isotonic buffer $(\mathrm{pH}$ $8.0 \pm 0.2)$, which contains Tris $(10 \mathrm{mM})$, EDTA $(10 \mathrm{mM})$, and $\mathrm{NaCl}(2.5 \%)$ and incubated overnight at $4^{\circ} \mathrm{C}$. After incubation, supernatant containing the cell-bound EPS was collected and pooled with CFCS. Then ice-cold ethanol was added with the aforesaid supernatant mixture at 2:1 ratio for precipitation. The precipitated cell-free and cell-bound EPS was collected by centrifugation at 12,000 rpm for $20 \mathrm{~min}$. Finally, the extracted EPS samples were weighed, and\% of EPS reduction was calculated using the formula (Control EPS wt - Treated EPS wt/Control EPS wt) $\times 100$.

\section{Fourier Transform Infrared Spectroscopy Analysis}

For Fourier transform infrared (FT-IR) analysis, an equal quantity of EPS extracted from HMB-treated and untreated $P$. mirabilis was pelletized separately with potassium bromide $(\mathrm{KBr})$ at 1:100 ratio under hydraulic pressure. The IR spectra of EPS samples were scanned in the spectral range of 2,000$500 \mathrm{~cm}^{-1}$ using FT-IR spectroscopy (Nicolet iS5, Thermo Fisher Scientific Inc., Canton, GA, United States). The spectra were plotted as absorbance versus wavenumber and analyzed for variations in EPS components using OMNIC software.

\section{Effect of 2-Hydroxy-4- Methoxybenzaldehyde on the Virulence Factors of Proteus mirabilis Urease Assay}

The effect of HMB on $P$. mirabilis urease production was determined by the procedure described Durgadevi et al. (2019) with modification. Briefly, $1 \%$ of $P$. mirabilis culture was allowed to grow in $1 \mathrm{ml}$ of urea broth [peptone $(1.5 \mathrm{~g} / \mathrm{L})$, sodium chloride (5 g/L), monopotassium phosphate $(2 \mathrm{~g} / \mathrm{L})$, and filter sterilized urea $(20 \mathrm{~g} / \mathrm{L})]$ supplemented with and without $\operatorname{HMB}(12.5,25$, and $50 \mu \mathrm{g} / \mathrm{ml}$ ) for $24 \mathrm{~h}$ at $37^{\circ} \mathrm{C}$. After incubation, $0.02 \%$ phenol red reagent ( $\mathrm{pH}$ indicator) was added to CFCS of both HMBtreated and untreated samples. Owing to the urease activity, the $\mathrm{pH}$ of the samples increases, which is indicated by the formation of pink color. Then, the color change was visually observed and spectroscopically measured at $\mathrm{OD}_{670 \mathrm{~nm}}$.

\section{Hemolysin Assay}

The effect of HMB on P. mirabilis hemolysin production was assessed by following the method of Subramenium et al. (2015). Briefly, an equal volume of CFCS of both HMB-treated (12.5, 25 , and $50 \mu \mathrm{g} / \mathrm{ml}$ ) and untreated samples was incubated with $2 \%$ of freshly collected sheep blood (in sterile phosphatebuffered saline [PBS] [v/v]) and incubated at $37^{\circ} \mathrm{C}$ for $1 \mathrm{~h}$. During the incubation period, the hemolysin enzyme lyses the red blood cells by destroying their cell membrane. And the released blood cell components were mixed with the sample, and its density was increased. Then, the cell-free supernatants were collected by centrifugation at 3,000 rpm for $5 \mathrm{~min}$ and 
spectroscopically measured at $\mathrm{OD}_{405} \mathrm{~nm}$ in order to quantify the hemolysin production.

\section{Siderophore Assay}

The effect of HMB on siderophore production by $P$. mirabilis was assessed by blue agar chrome azurol sulfonate (CAS) assay. CAS agar was prepared by a step-by-step procedure as described by Louden et al. (2011) with minor modification. Briefly, 0.3\% of piperazine- $N, N^{\prime}$-bis(2-ethanesulfonic acid) (PIPES; HiMedia, Mumbai) was added to $10 \mathrm{ml}$ of Minimal Media 9 (MM9) salt solution $\left(3 \% \mathrm{KH}_{2} \mathrm{PO}_{4}, 10 \% \mathrm{NH}_{4} \mathrm{Cl}\right.$, and $\left.5 \% \mathrm{NaCl}\right)$. Then, seven volumes of $\mathrm{ddH}_{2} \mathrm{O}$ and $2 \%$ of agar were added to the MM9/PIPES mixture, and its $\mathrm{pH}$ was adjusted to 6.8 using $0.1 \mathrm{~N}$ of $\mathrm{NaOH}$ solution. Simultaneously, blue dye was prepared by pooling the three individual solutions including $0.1 \% \mathrm{CAS}, 0.03 \% \mathrm{FeCl}_{3}$, and $0.2 \%$ hexadecyl trimethyl ammonium bromide (HiMedia, Mumbai) at 5:1:4 ratio. The prepared MM9/PIPES and blue dye solutions were autoclaved separately and cooled to $50^{\circ} \mathrm{C}$. The CAS agar was prepared by pooling the filter sterilized tryptone (10\%; HiMedia, Mumbai) and glucose (20\%; HiMedia, Mumbai) solutions with MM9/PIPES mixture. Finally, the blue dye was gradually added to the CAS agar and mixed thoroughly. The prepared CAS agar was supplemented with and without of HMB (MBIC) and poured aseptically into sterile petri plates. Then, $2 \mu \mathrm{l}$ of bacterial culture was placed at the center of these CAS agar plates. After incubation for a period of $24 \mathrm{~h}$, the plates were analyzed for the zone of siderophore activity.

\section{Crystalline Biofilm Production}

Owing to urease activity, P. mirabilis produces crystalline biofilm in the presence of urinary components such as urea, chloride, sodium, potassium, and other dissolved ions, and organic and inorganic compounds. For this study, artificial urine (AU) media was prepared in accordance with the procedure described by Durgadevi et al. (2019) with minor changes. Briefly, 0.05\% calcium chloride, $0.07 \%$ magnesium chloride, $0.2 \%$ sodium disulfate, $0.5 \%$ sodium chloride, $0.002 \%$ sodium oxalate, $0.06 \%$ trisodium citrate, $0.1 \%$ ammonium chloride, $0.3 \%$ potassium dihydrogen orthophosphate, $0.2 \%$ potassium chloride, and $2.5 \%$ urea were dissolved in sterile distilled water. Then, the $\mathrm{pH}$ of the prepared AU media was adjusted to $6.2 \pm 0.2$ and sterilized using a cellulose nitrate membrane filter $(0.2 \mu \mathrm{m}$; Sartorius, United Kingdom). Finally, the filtered AU medium was aseptically pooled with equal volume of sterile $2 \times$ LB medium for experimental purposes.

\section{Characterization Analysis}

Proteus mirabilis culture was allowed to grow in AU media at $37^{\circ} \mathrm{C}$ for $24 \mathrm{~h}$. After incubation, the planktonic cells were discarded, and the crystal precipitates (due to generation of alkaline environment) were collected and dried by vacuum drier. Further, the qualitative analysis of the precipitated struvite/apatite crystals was carried out by X-ray diffraction (XRD) spectrophotometer (X'pert Pro; PANalytical, Almelo, Netherlands) and FT-IR spectroscopy (Nicolet iS5, Thermo Fisher Scientific Inc., Canton, GA, United States) to determine its degree of crystallization as well as the presence of inorganic chemical composition.

\section{Crystalline Biofilm Inhibition Assay}

The effect of $\mathrm{HMB}$ on $P$. mirabilis crystalline biofilm formation was assessed by microbroth dilution method as aforementioned. Briefly, $1 \%$ of $P$. mirabilis culture was allowed to grow in AU media supplemented with and without $\operatorname{HMB}(25,50$, and $100 \mu \mathrm{g} / \mathrm{ml}$ ) for $24 \mathrm{~h}$ at $37^{\circ} \mathrm{C}$. Then, the crystalline biofilm production in the presence and absence of $\mathrm{HMB}$ was quantified by $\mathrm{CV}$ staining method. In addition, the anti-crystalline biofilm efficacy of $\mathrm{HMB}$ against $P$. mirabilis was observed by LM and CLSM techniques. For this, the samples were prepared as mentioned above.

\section{Scanning Electron Microscopy and Energy-Dispersive X-Ray Analysis}

To analyze the effect of HMB on P. mirabilis crystalline biofilm production, FESEM with energy-dispersive X-ray (EDAX) analysis was performed. P. mirabilis was allowed to grow on glass slides immersed in AU media supplemented with and without HMB (MBIC). Then the crystalline biofilm of control and treated slides were documented under SEM, and the level of struvite/apatite composition present in both samples was also examined by EDAX analysis.

\section{Survivability of Proteus mirabilis in Human Blood}

The effect of HMB on cellular viability of $P$. mirabilis in blood serum was assessed by blood survival assay as described by Viszwapriya et al. (2016). P. mirabilis cell suspension was incubated with freshly collected human blood sample at 1:4 ratio in the absence and presence of HMB (at MBIC) for $3 \mathrm{~h}$ at $37^{\circ} \mathrm{C}$. After incubation, HMB-treated and untreated blood samples were serially diluted and spread over LB agar plate to analyze the number of viable cells present in the HMB-treated and untreated samples.

\section{Motility Assessment}

The effect of HMB on P. mirabilis swimming as well as swarming motility was analyzed as described by Liaw et al. (2000) with little modification. Initially, agar medium in the presence and absence of HMB (MBIC) was prepared for swarming and swimming motility assays separately. For assessing swarming motility, $3 \mu \mathrm{l}$ of $P$. mirabilis culture was spot inoculated on the surface of LB agar plate ( $1 \%$ peptone, $0.5 \% \mathrm{NaCl}$, and $1.5 \%$ agar). For swimming motility, $5 \mu \mathrm{l}$ of culture was stab inoculated at the center of semisolid LB agar plate ( $1 \%$ peptone, $0.5 \% \mathrm{NaCl}$, and $0.5 \%$ agar). The plates were then incubated at $37^{\circ} \mathrm{C}$ for $24 \mathrm{~h}$ with lid position facing upward.

\section{Live/Dead Staining Assay}

Confocal laser scanning microscopic analysis was performed to evaluate the mature biofilm (24-h-old) disruption ability of HMB using live/dead staining (BacLight cell viability staining kit, Molecular Probes, Eugene, OR, United States). Briefly, 
P. mirabilis strains ATCC and CI were allowed to form biofilm on glass slides for $24 \mathrm{~h}$ at $37^{\circ} \mathrm{C}$. Then, the planktonic cells were discarded, and the glass slide-bound biofilm was submerged in sterile $1 \times$ PBS supplemented with and without HMB $(1 \times$ and $2 \times \mathrm{MBIC})$ and incubated for another $24 \mathrm{~h}$. At the end of incubation, the slides were washed and stained with a mixture of propidium iodide (PI) and SYTO9 $(1 \mu \mathrm{M}$ of concentration each). The stained biofilm slides were documented under CLSM and examined with Zeiss LSM Image Browser (version 4.2.0.121).

\section{Quantitative Real-Time PCR Analysis}

The total RNA was isolated from HMB-treated (MBIC) and untreated $P$. mirabilis by Trizol method. Then reverse transcription PCR was performed to convert the isolated RNA into cDNA using high capacity reverse transcriptase kit (Applied Biosystems Inc., United States). After that, quantitative realtime PCR (qRT-PCR) analysis was performed using SYBR Green PCR Master Mix in 7500 Sequence Detection System (Applied Biosystems Inc., United States). For qRT-PCR analysis, the expression of virulence genes $(f l h B, f l h D, r s b A$, speA, ureR, hpmA, and $h p m B$ ) was analyzed using gene-specific primers listed in Table 1. Then, the housekeeping gene rplS was used as an internal control to normalize the expression levels of the candidate genes (Ravindran et al., 2018).

\section{Assessment of Cytotoxicity of 2-Hydroxy-4-Methoxybenzaldehyde}

The effect of HMB on human embryonic kidney cells (HEK293) was assessed by MTT assay. Initially, $10^{4}$ cells/well of HEK-293 were seeded with Dulbecco's modified Eagle medium (DMEM) (supplemented with $10 \%$ fetal bovine serum) in a $96-$ well microtiter plate and incubated in $\mathrm{CO}_{2}$ incubator at $37^{\circ} \mathrm{C}$ for $24 \mathrm{~h}$. After incubation, the cells were exposed to different concentrations of HMB $(25-500 \mu \mathrm{g} / \mathrm{ml})$ supplemented in the medium and incubated for $24 \mathrm{~h}$. Then, the medium was aspirated and added with $10 \mu \mathrm{l}$ of MTT from $5 \mathrm{mg} / \mathrm{ml}$ stock (prepared in PBS) and incubated for an additional $3 \mathrm{~h}$. The formazan crystals that formed at the end of incubation period were dissolved using DMSO, and the absorbance of the solution was measured at $\mathrm{OD}_{590 \mathrm{~nm}}$ in order to quantify the cytotoxicity of HMB.

Further, fluorescence microscopy analysis was performed to investigate the viability of HEK-293 cells under HMB (25$500 \mu \mathrm{g} / \mathrm{ml}$ ) treatment. The HMB-treated and untreated cell lines were stained with a mixture of live/dead stains such as AO and ethidium bromide dyes (1:1 ratio), respectively. Then, the stained cells were imaged under inverted fluorescence microscope (AccuScope EXI-310).

\section{Statistics}

In this study, all the in vitro experiments were performed in triplicate and repeated at least thrice. IBM SPSS statistics 23 (SPSS Ltd., Hong Kong) software package was used for statistical analysis. All data were analyzed using either one-way ANOVA or Student's $T$-test for comparing the differences between control and treated samples.

\section{RESULTS}

\section{Antibacterial and Antibiofilm Activity of 2-Hydroxy-4-Methoxybenzaldehyde}

The antibacterial activity of $\mathrm{HMB}$ against both $P$. mirabilis ATCC and CI was studied by broth dilution method. MIC was determined at $200 \mu \mathrm{g} / \mathrm{ml}$ concentration of $\mathrm{HMB}$, wherein the visible growth of $P$. mirabilis strains was completely reduced (Figures 1A,B). Further, the antibiofilm efficacy of HMB was evaluated by biofilm biomass quantification method, and the results exhibited a concentration-dependent biofilm inhibition (Figures 1A,B). MBIC was determined as the minimum concentration of $\mathrm{HMB}$ that reduces the maximum biofilm production in $P$. mirabilis. MBIC of HMB was found to be $50 \mu \mathrm{g} / \mathrm{ml}$, at which a maximum $80 \%$ of biofilm inhibition in P. mirabilis ATCC and $70 \%$ of biofilm inhibition in P. mirabilis CI were observed without any deleterious effect on the growth of planktonic cells. Thus, MBIC of HMB was used to carry out all virulence assays.

Further, the non-bactericidal antibiofilm property of $\mathrm{HMB}$ was validated by XTT reduction assay. The obtained result shows that the level of colored formazan production, indicating the presence of metabolic activity is the same in both HMBtreated and untreated culture. This observation concludes that the $\mathrm{HMB}$ (up to MBIC) treatment did not show any lethal effect on the cellular viability of $P$. mirabilis ATCC and CI (Supplementary Figure S1).

\section{Microscopic Analysis}

The LM and CLSM analyses revealed the antibiofilm potential of HMB against $P$. mirabilis ATCC and CI strains wherein the biofilm architecture in HMB-treated slides was slackened and poorly formed than that of their respective untreated control slides (Figures 1C,D). Further, SEM analysis clearly portrayed that $\mathrm{HMB}$ effectually reduced biofilm-associated bacterial cells, whereas the control image showed an unimpaired and well-developed biofilm structure (Supplementary Figure S2).

\section{Effect of 2-Hydroxy-4- Methoxybenzaldehyde on Exopolysaccharide Production}

The quantification of EPS unveiled that HMB significantly reduced the EPS production. A maximum of 60 and $51 \%$ reduction was observed at $\mathrm{MBIC}$ of $\mathrm{HMB}$ treatment in P. mirabilis ATCC and CI, respectively (Figure 2A). In FT-IR analysis, the IR spectra of EPS samples extracted from the control and HMB-treated (MBIC) $P$. mirabilis culture exhibited indistinguishable peak positions at 1,5001,700 and $1,300-900 \mathrm{~cm}^{-1}$, which corresponded to the proteins and mixed region of carbohydrates and nucleic acids, respectively (Durgadevi et al., 2019). However, the absorbance intensities of these spectral regions were found to be decreased in the EPS of HMB-treated P. mirabilis samples than those of the EPS of untreated control $P$. mirabilis samples (Figure 2C). This observation emphasizes that the production 
TABLE 1 | List of virulence genes in P. mirabilis and their primer sequences.

\begin{tabular}{|c|c|c|c|c|}
\hline \multirow[t]{2}{*}{ Gene } & \multirow[t]{2}{*}{$\operatorname{Tm}\left({ }^{\circ} \mathbf{C}\right)$} & \multirow[t]{2}{*}{ Accession numbers } & \multicolumn{2}{|c|}{ Primers } \\
\hline & & & Forward primer & Reverse primer \\
\hline$f / h B$ & 56 & KGA90550 & TCAGCTAACGCATTCATTG & GCCAGTGTITCTAGGCTTG \\
\hline$f / h D$ & 56 & TFU19979 & CTTCCGCAATGTTAAGACTG & ATTTGTTGCAAATCATCCAC \\
\hline$r s b A$ & 58 & AAC82660 & AAAATACAAGGCACTITGACC & TATCAAGCTGTTGGCAGATTA \\
\hline speA & 57 & QES78361 & CATCTGTGATCCAAGGTGAA & GCCGAACGTITAGAAGTGAT \\
\hline ure $R$ & 56 & CAA79243 & GGATGTAGCAAAAACGCTCT & ATGCGTCACAAAAATAAGCA \\
\hline hpmA & 67 & WP_149127624 & GTTGAGGGGCGTTATCAAGAGTC & GATAACTGПITGCCCTाTGTGC \\
\hline hpmB & 60 & WP_143475422 & CAGTGGATTAAGCGCAAATG & ССТTCAATACGTTCAACAAACC \\
\hline rp/s & 58 & TFU20016 & CGAACAAGAACAAATGAAGC & GGGGAGTGAGTाGGAATAC \\
\hline
\end{tabular}
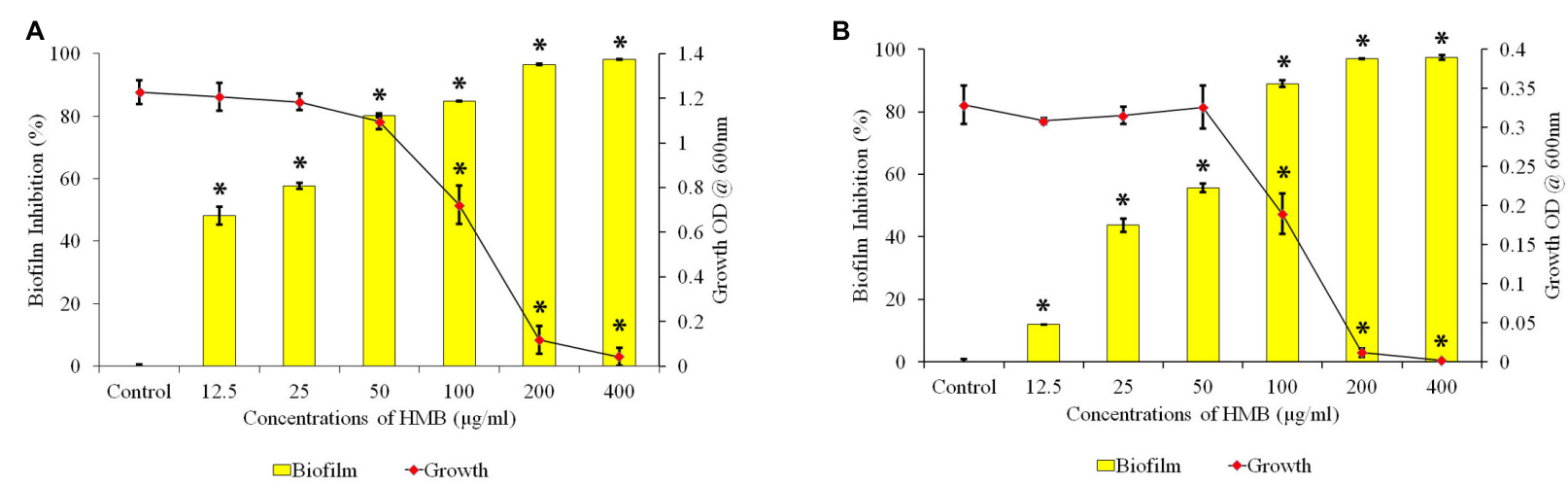

C

(a)

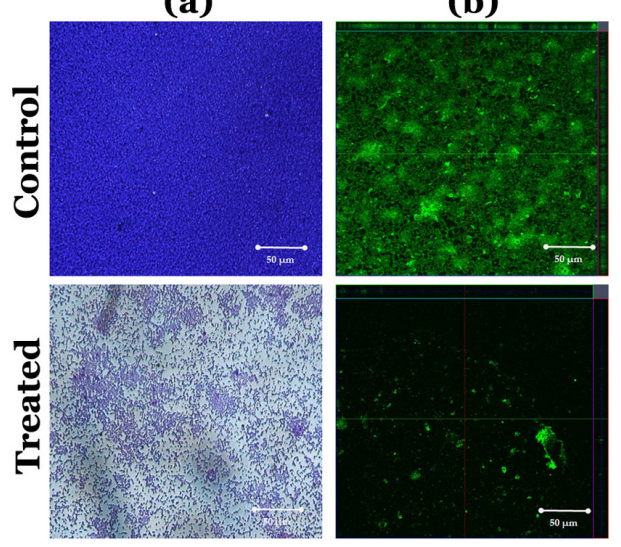

(a)

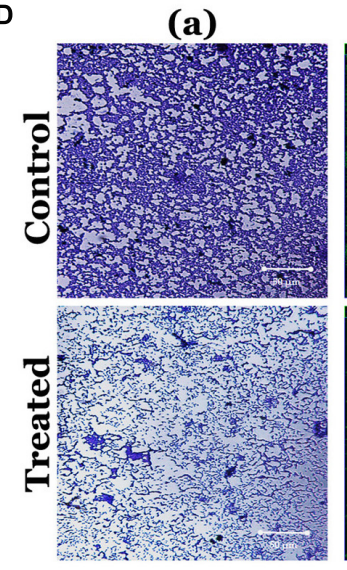

(b)

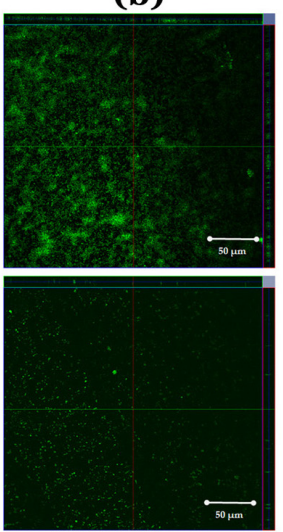

FIGURE 1 | Effect of HMB (at its MBIC) on growth and biofilm of Proteus mirabilis (A) ATCC and (B) Cl. Data represent mean values $(n=3) \pm$ standard deviation. * indicates significance at $P<0.005$. Microscopic analysis of $P$. mirabilis (C) ATCC and (D) $\mathrm{Cl}$ in the absence and presence of HMB at MBIC. (a) LM (400x magnification) and (b) CLSM (scale bar $=50 \mu \mathrm{m}$ ) images clearly portray a significant reduction in biofilm thickness of HMB (MBIC)-treated samples compared with untreated control. HMB, 2-hydroxy-4-methoxybenzaldehyde; MBIC, minimum biofilm inhibitory concentration; ATCC, American Type Culture Collection; Cl, clinical isolate; LM, light microscopy; CLSM, confocal laser scanning microscopy.

of EPS components in P. mirabilis were efficiently inhibited upon HMB treatment.

\section{Quantification of Urease and Hemolysin Production}

The urease and hemolysin are the most important virulence factors produced by $P$. mirabilis to cause complicated CAUTIs. The results showed a maximum 63 and $46 \%$ of urease inhibition, and 75 and $51 \%$ of hemolysin inhibition upon treatment with HMB (MBIC) in P. mirabilis ATCC and CI, respectively (Figure $2 \mathrm{~A}$ ).

\section{Siderophore Inhibition}

Proteus mirabilis produces iron-scavenging molecule siderophore, which is essential for its growth and biofilm development under iron-deficient conditions like human urinary 

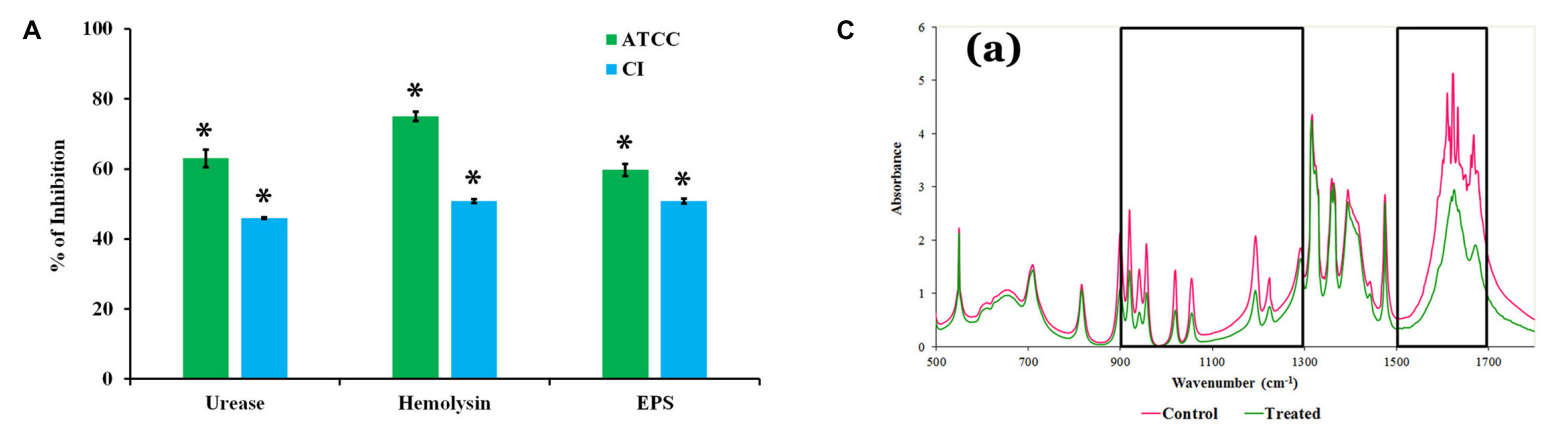

B (a)

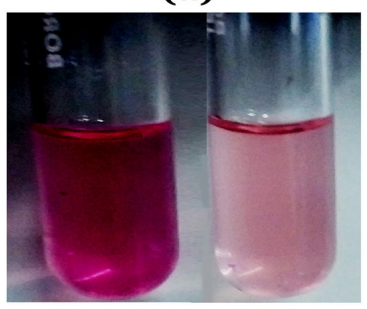

Control

Treated
D

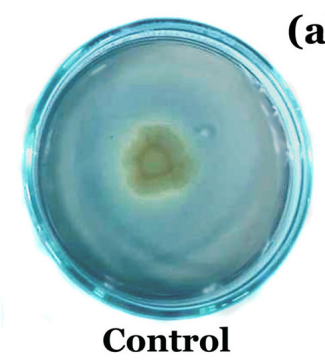

(a)

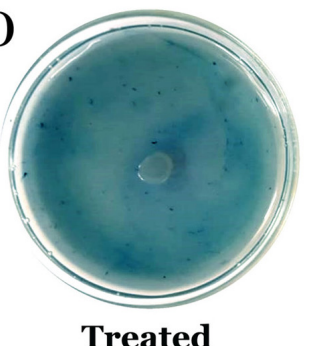

Treated (b)

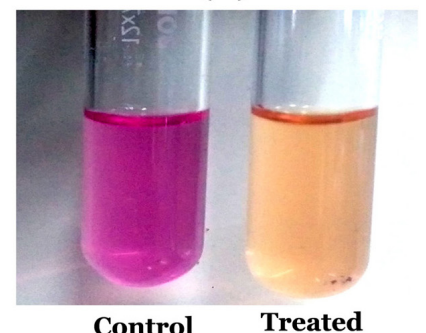

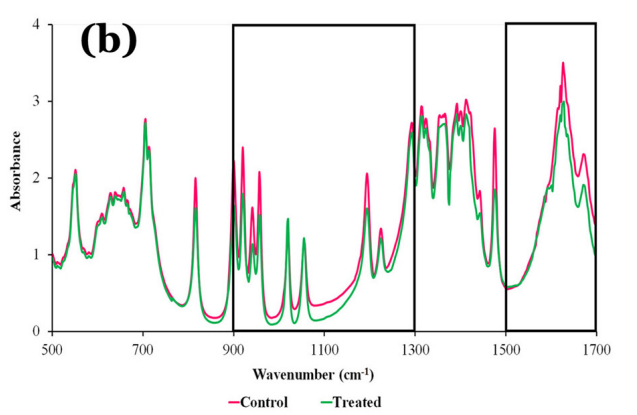

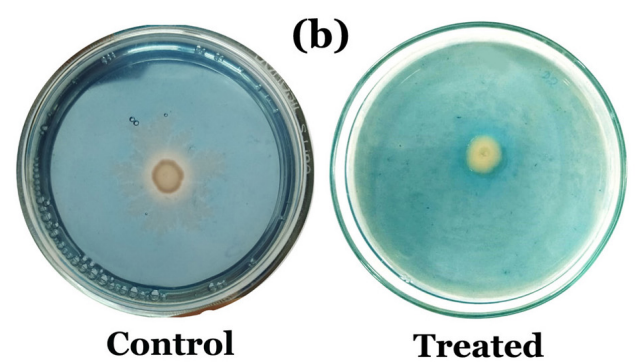

FIGURE 2 | (A) Effect of HMB (at its MBIC) on Proteus mirabilis virulence factors such as urease, hemolysin, and EPS production. Data represent mean values $(n=3) \pm$ standard deviation. * indicates significance at $P<0.005$. (B) Representative images of test tubes displaying urease inhibitory potential of $\mathrm{HMB}$ (MBIC) on P. mirabilis (a) ATCC and (b) Cl. (C) FT-IR analysis of the EPS samples extracted from the HMB-treated (at its MBIC) and untreated P. mirabilis (a) ATCC and (b) Cl. Boxl represents the region of polysaccharides and nucleic acids (1,300-900 $\left.\mathrm{cm}^{-1}\right)$, and box II represents the region of proteins (1,500-1,700 $\left.\mathrm{cm}^{-1}\right)$.

(D) Siderophore inhibitory potential of HMB at its MBIC on P. mirabilis (a) ATCC and (b) Cl. HMB, 2-hydroxy-4-methoxybenzaldehyde; MBIC, minimum biofilm inhibitory concentration; EPS, exopolysaccharide; ATCC, American Type Culture Collection; Cl, clinical isolate; FT-IR, Fourier transform infrared.

tract system (Banin et al., 2005; Himpsl et al., 2010). Hence, attenuation of siderophores production could be considered as one of the possible ways to prevent P. mirabilis-mediated UTI. The HMB effectually inhibited the siderophore production in both ATCC and CI of P. mirabilis at its MBIC. A pale yellow zone of siderophore activity was observed around untreated $P$. mirabilis colonies in blue dye background, which has occurred via removal of iron content from the CAS, whereas in HMBtreated CAS agar plates, the zone of siderophore activity was found to have disappeared (Figure 2D).

\section{Crystalline Biofilm Formation by Proteus mirabilis}

The urease production by $P$. mirabilis causes obstruction and encrustation of urethral catheters via crystalline biofilm formation. Initially, owing to the urease activity of $P$. mirabilis, the local environmental $\mathrm{pH}$ greatly increases, which leads to the precipitation of soluble ions as struvite/apatite crystals in AU media. In this study, the FT-IR analysis was performed to confirm the production of struvite/apatite crystal precipitates. FT-IR spectrum of this salt precipitant shows high intensity IR bands at 3,411,2,957, 2,857, 1,653, 1,571, 1,406, 1,077, 882, and $558 \mathrm{~cm}^{-1}$ regions, which corresponds to the presence of water of hydration, $\mathrm{N}-\mathrm{H}$ bond, $\mathrm{P}-\mathrm{O}$ bond, $\mathrm{NH}_{4}{ }^{+}$ion and $\mathrm{PO}_{4}{ }^{3-}$ ion, and metal-oxygen bond. According to the previous report of Chauhan and Joshi (2013), the principal IR bands observed in FT-IR spectra of crystal precipitate are speculated to represent the presence of main components of struvite/apatite such as magnesium, ammonium, and calcium phosphates (Figure 3A).

Moreover, the crystallite nature of these salt precipitates was revealed by XRD analysis. Figure 3B shows sharp XRD peaks 
A

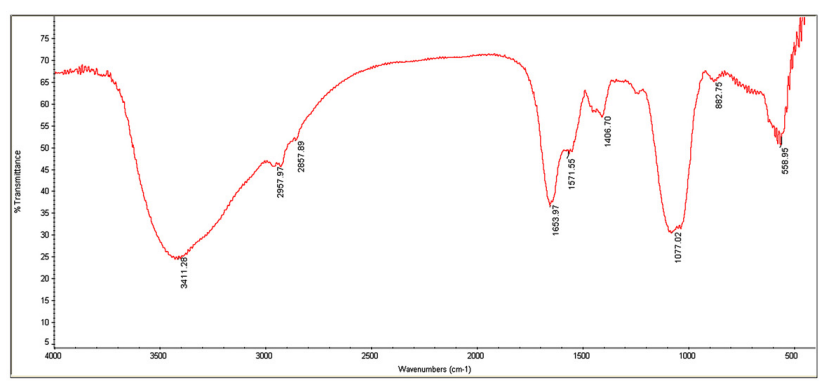

B

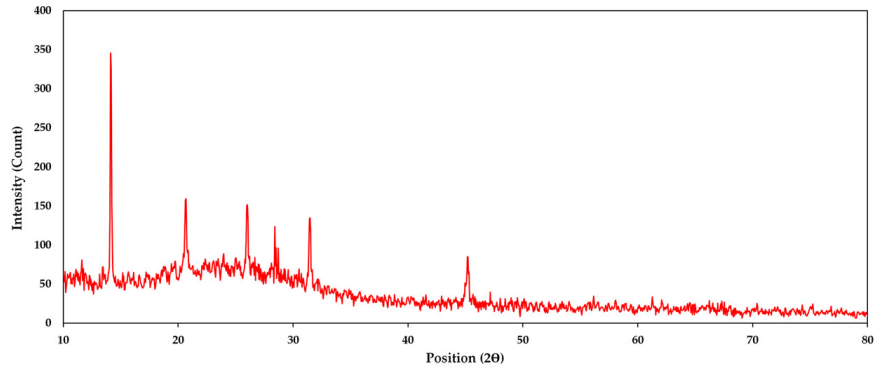

D

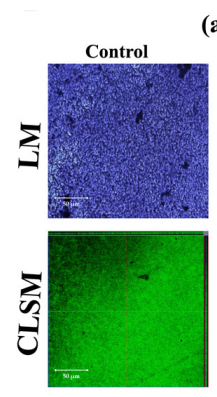

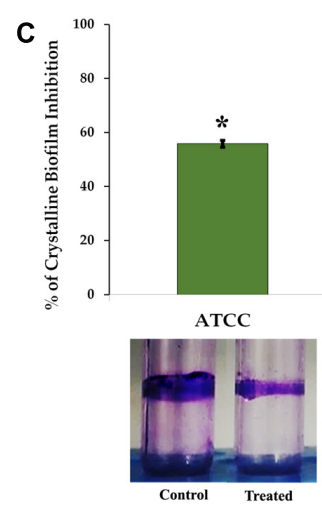

(a)

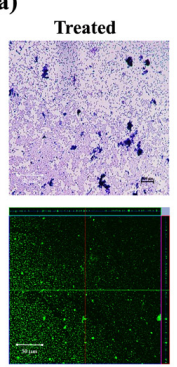

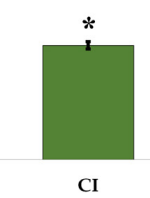

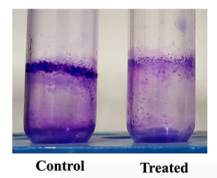

(b)

FIGURE 3 | Crystalline biofilm production. (A) FT-IR and (B) XRD analyses of struvite/apatite crystal precipitates. (C) Assessment of HMB (at its MBIC) on crystalline biofilm of Proteus mirabilis. Data represent mean values $(n=3) \pm$ standard deviation. * indicates significance at $P<0.005$. (D) Microscopic (LM and CLSM) analysis of $P$. mirabilis (a) ATCC and (b) Cl crystalline biofilm formation in the presence and absence of HMB at MBIC. FT-IR, Fourier transform infrared; XRD, X-ray diffraction; HMB, 2-hydroxy-4-methoxybenzaldehyde; MBIC, minimum biofilm inhibitory concentration; LM, light microscopy; CLSM, confocal laser scanning microscopy; Cl, clinical isolate.

at $14.15^{\circ}, 20.67^{\circ}, 26.02^{\circ}, 28.42^{\circ}, 31.46^{\circ}$, and $45.57^{\circ}$, indicating the formation of well crystalline level of salt precipitants. The $2 \theta$ values were also found to be closely matching those of the previous report of Possenti et al. (2019), wherein the XRD patterns of struvite (peaks at $14.99^{\circ}, 15.81^{\circ}, 16.47^{\circ}, 20.85^{\circ}$, $21.45^{\circ}, 27.07^{\circ}$, and $31.94^{\circ}$ ) and apatite (peak at $\sim 25.90^{\circ}$ ) were depicted by comparing them with the Inorganic Crystal Structure Database (ICSD nos. 014269 and 016132). Altogether, the obtained results revealed the presence of magnesium ammonium phosphate and calcium phosphate crystals in the salt precipitates produced by $P$. mirabilis.

\section{Impact of 2-Hydroxy-4- Methoxybenzaldehyde on Crystalline Biofilm Production}

The urease production by $P$. mirabilis causes obstruction and encrustation of urethral catheters via crystalline biofilm formation. Hence, the present study evaluates the potential of $\mathrm{HMB}$ on $P$. mirabilis crystalline biofilm production. HMB at MBIC exhibited 55 and $42 \%$ reduction of crystalline biofilm production in $P$. mirabilis ATCC and CI, respectively (Figure 3C). Further, the crystalline biofilm inhibitory potential of HMB was validated through LM and CLSM analyses wherein loosely attached microcolonies were observed in HMB-treated micrographs, whereas multilayered biofilm matrix was observed in the micrographs of untreated control samples of P. mirabilis ATCC and CI (Figure 3D).

\section{Scanning Electron Microscopy and Energy-Dispersive X-Ray Analysis}

The FESEM analysis of $P$. mirabilis crystalline biofilm upon HMB treatment further validated the result of in vitro crystalline biofilm inhibition assay. In Figure $\mathbf{4 A}$, the FESEM image of HMB-treated sample shows highly reduced crystalline biofilm formation, whereas the untreated control image shows densely formed crystalline biofilm matrix.

Also, the efficacy of HMB on the production of struvite/apatite salt crystals by $P$. mirabilis was evaluated by FESEM and EDAX analyses. Owing to the urease activity of $P$. mirabilis, soluble ions in urine will be precipitated normally as struvite/apatite. These precipitated crystals can grow to remarkable size and produce kidney stones as well as crystalline biofilm. In this study, the FESEM analysis revealed the struvite crystals as well as crystalline biofilm inhibitory efficacy of HMB. Figure $4 B$ shows a high level of salt crystals in biofilm matrix of untreated control sample, whereas the HMB-treated sample shows only a low quantity of salt crystal precipitates. Meanwhile, EDAX analysis was performed to quantify the level of struvite components in the crystalline biofilm of $P$. mirabilis upon $\mathrm{HMB}$ treatment. In Figure 4C, it is seen that the peak intensity of crystallized struvite components such as calcium, magnesium, and phosphorus was 

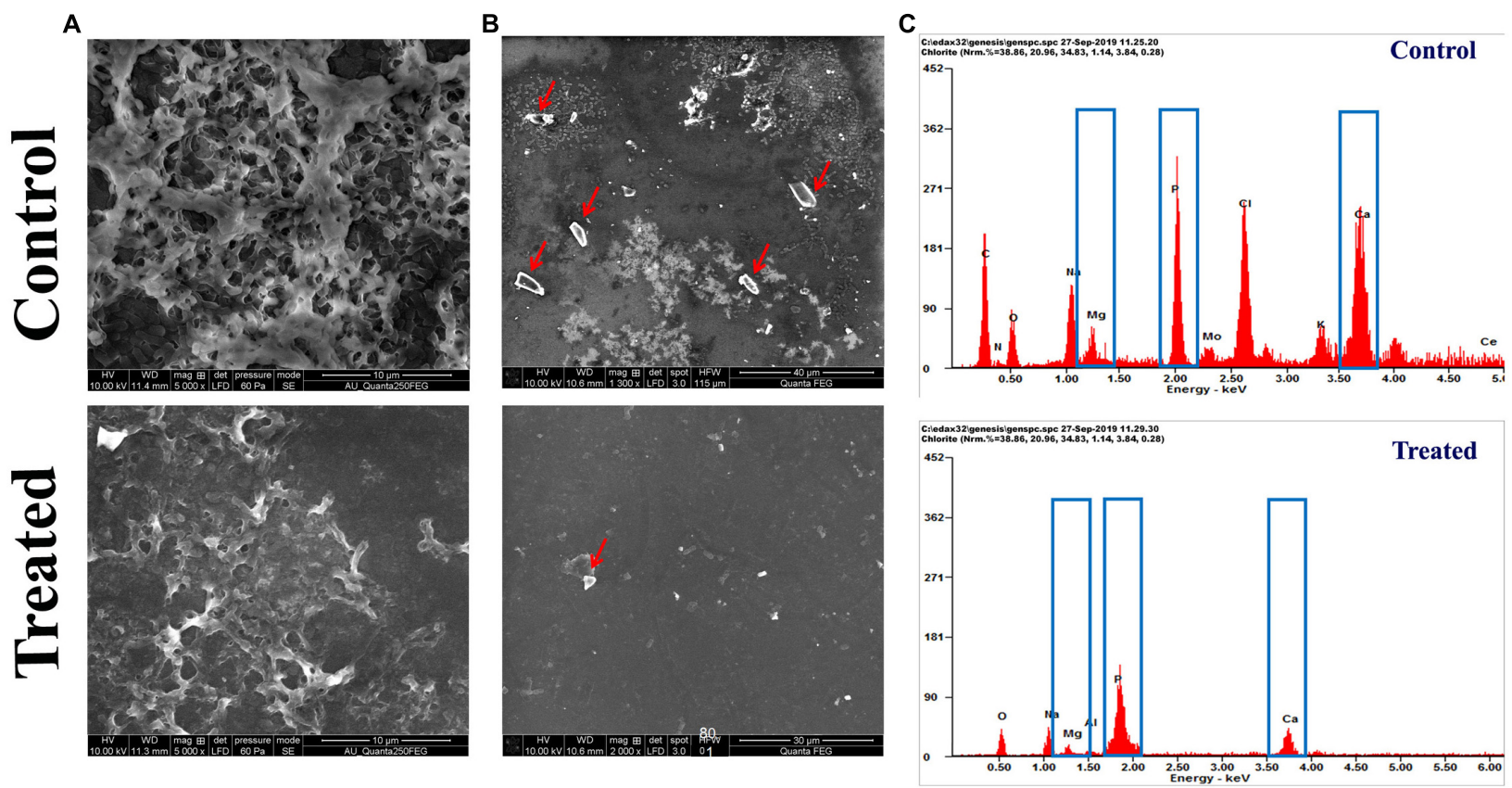

FIGURE 4 | Effect of HMB (at its MBIC) on Proteus mirabilis crystalline biofilm production. FESEM analysis of (A) crystalline biofilm matrix and (B) formation of salt crystal precipitates (indicated by red arrow) and (C) energy-dispersive X-ray EDAX analysis of $P$. mirabilis struvite production in the presence and absence of $\mathrm{HMB}$ at MBIC. HMB, 2-hydroxy-4-methoxybenzaldehyde; MBIC, minimum biofilm inhibitory concentration; EDAX, energy-dispersive X-ray.

highly reduced in HMB (MBIC)-treated sample in comparison with the untreated control.

\section{Effect of 2-Hydroxy-4- Methoxybenzaldehyde on Proteus mirabilis Viability in Human Blood}

Proteus mirabilis can potentially invade into the bloodstream from the upper urinary system, which further leads to septicemia. This is typically observed as the result of urinary catheterization or kidney infection. Thus, the efficacy of HMB treatment on cellular viability of $P$. mirabilis in human blood was assessed. HMB treatment efficiently reduced the total number of $P$. mirabilis cells in the blood sample than that of untreated control (Figure 5). Hence, the present study revealed that HMB enhances the susceptibility of $P$. mirabilis to human serum.

\section{Anti-swimming and Anti-swarming Activity of 2-Hydroxy-4- Methoxybenzaldehyde}

The flagella-mediated swimming and swarming motilities are the most important characteristic features of $P$. mirabilis pathogenicity, which facilitate the dissemination of the infection from urinary catheter to bladder and other parts of the host system (Jones et al., 2005). Hence, the efficacy of HMB on the motility of $P$. mirabilis was evaluated. The obtained results divulged that $\mathrm{HMB}$ (MBIC) effectually suppressed the swarming as well as swimming motilities in both ATCC and CI of $P$. mirabilis. In Figure 6, it is seen that the distance of bacterial motility from the inoculum point was highly reduced in the HMB-treated plates compared with their respective control plates.

\section{Effect of 2-Hydroxy-4- Methoxybenzaldehyde on Proteus mirabilis Preformed Biofilm}

The live/dead staining method was performed to divulge the killing efficacy of $\mathrm{HMB}$ against biofilm-associated cells of P. mirabilis ATCC and CI. The CLSM micrographs of HMB $(1 \times$ and $2 \times \mathrm{MBIC})$-treated samples showed an elevated level of red fluorescence (PI), which indicates the dead cells, whereas the untreated control images displayed a high intensity of green fluorescence due to SYTO9, which specifically stains viable cells (Figure 7). This observation clearly revealed the concentration-dependent killing efficacy of HMB on biofilmembedded $P$. mirabilis cells.

\section{Effect of 2-Hydroxy-4- Methoxybenzaldehyde on Proteus mirabilis Virulence Gene Expression}

The relative expression level of $P$. mirabilis virulence traits under HMB (MBIC) treatment was assessed by transcriptomic analysis. The obtained result exhibited that the genes $f l h B, f l h D, s p e A, u r e R$, $h p m A$, and $h p m B$ are significantly downregulated. Meanwhile, there was no significant relative fold change in $r s b A$ gene upon HMB treatment (Figure 8). 

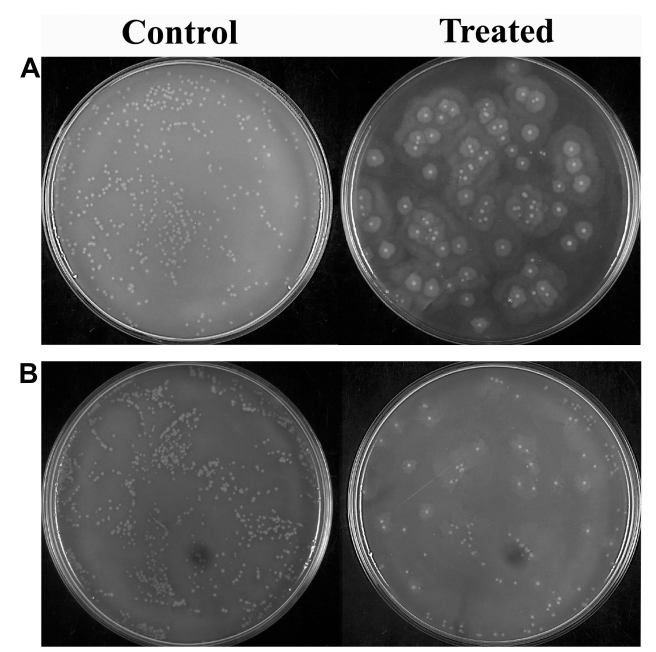

FIGURE 5 | Effect of HMB on blood survivability of Proteus mirabilis (A) ATCC and (B) Cl. Representative images clearly depict the efficient inhibition of blood survival rate of $\mathrm{HMB}$ (at its $\mathrm{MBIC}$ ) treated sample when compared with control. HMB, 2-hydroxy-4-methoxybenzaldehyde; ATCC, American Type Culture Collection; $\mathrm{Cl}$, clinical isolate; $\mathrm{MBIC}$, minimum biofilm inhibitory concentration.

\section{Efficacy of 2-Hydroxy-4- \\ Methoxybenzaldehyde on HEK-293 Cells}

The non-cytotoxic nature of HMB on HEK-293 cell lines was analyzed by MTT assay. As the concentration of HMB increases, no obvious change was observed in the cell viability upon comparison with control (Figure 9A). To ensure the same, fluorescence microscopic analysis was performed using live/dead staining. To a concentration of $100 \mu \mathrm{g} / \mathrm{ml}(2 \times \mathrm{MBIC})$, green fluorescence was observed, which divulges the presence of metabolically viable cells. Meanwhile, less number of dead (red fluorescence) cells were observed in HMB-treated (250 and $500 \mu \mathrm{g} / \mathrm{ml}$ ) groups, which specifies the non-toxic nature of HMB on HEK-293 cells (Figure 9B).

\section{DISCUSSION}

Proteus mirabilis forms extensive crystalline biofilm on indwelling urinary catheters, which blocks urine flow and leads to severe clinical complications. Generally, antibiotic treatment and recurrent catheter changes are ineffective in resolving P. mirabilis infections, especially catheter blockages and kidney infections (Sabbuba et al., 2003; Stickler and Jones, 2008). Therefore, there is a need to develop an alternative treatment strategy to combat biofilm-associated Proteus infections. To cope with this issue, this study was intended to delve into antibiofilm and antivirulence activity of HMB against $P$. mirabilis crystalline biofilm production. Unlike antimicrobial therapy, the probability of resistance development by pathogens upon treatment with antibiofilm agents is extensively low, as they specifically target virulence factor secretion that ruffles pathogenicity without affecting the metabolic viability of the pathogen (Srinivasan et al., 2018; Martínez et al., 2019).

In the present study, $\mathrm{HMB}$ was found to be effective in reducing the biofilm production of $P$. mirabilis ATCC and clinical strain in concentration-dependent manner. HMB showed maximum reduction in biofilm at MBIC $(50 \mu \mathrm{g} / \mathrm{ml})$ with no adverse effects on $P$. mirabilis growth. The results of XTT reduction assay also affirmed the non-bactericidal antibiofilm property of HMB. Further, microscopic analysis also validated the antibiofilm potential of $\mathrm{HMB}$ against $P$. mirabilis strains. The biofilm architecture in HMB-treated slides was diminished and poorly developed when compared with that of the untreated control. With this observation, HMB treatment is envisaged to control the biofilm-related infections caused by P. mirabilis.
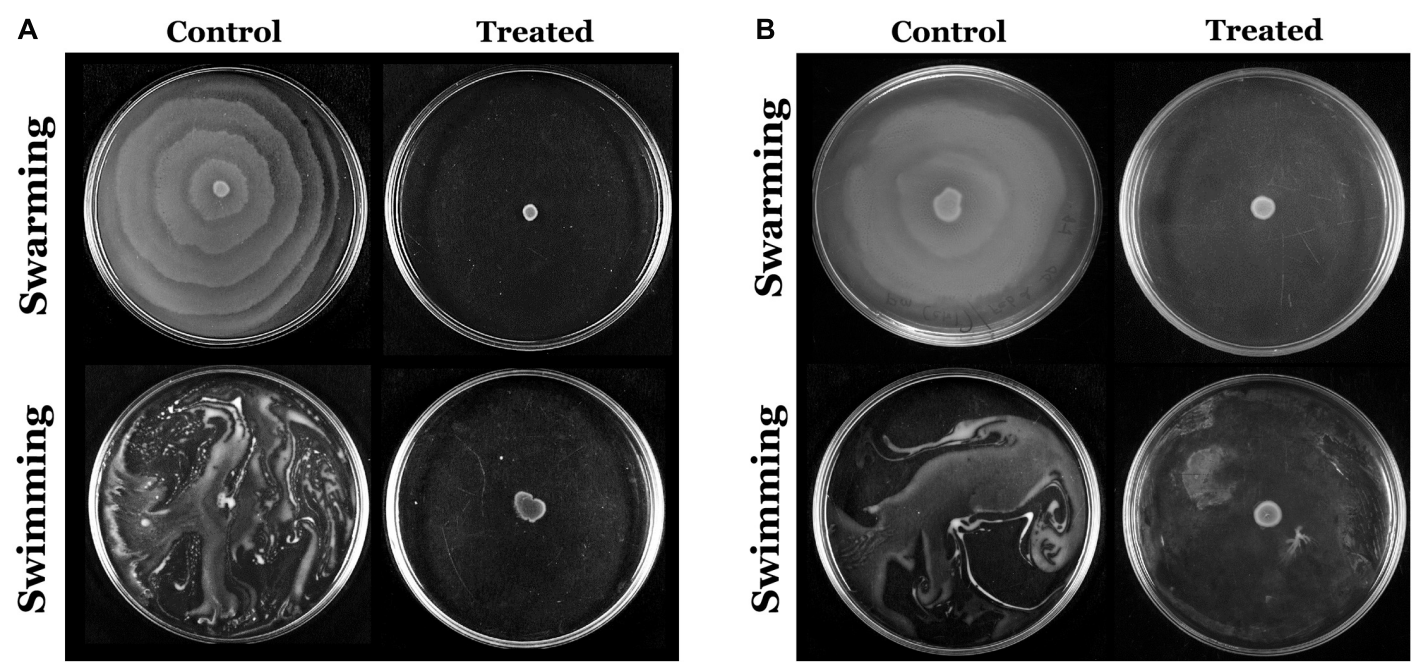

FIGURE 6 | Assessment of inhibitory efficacy of $\mathrm{HMB}$ (at its MBIC) on swarming and swimming motility of Proteus mirabilis (A) ATCC and (B) CI. HMB, 2-hydroxy-4-methoxybenzaldehyde; MBIC, minimum biofilm inhibitory concentration; ATCC, American Type Culture Collection; Cl, clinical isolate. 


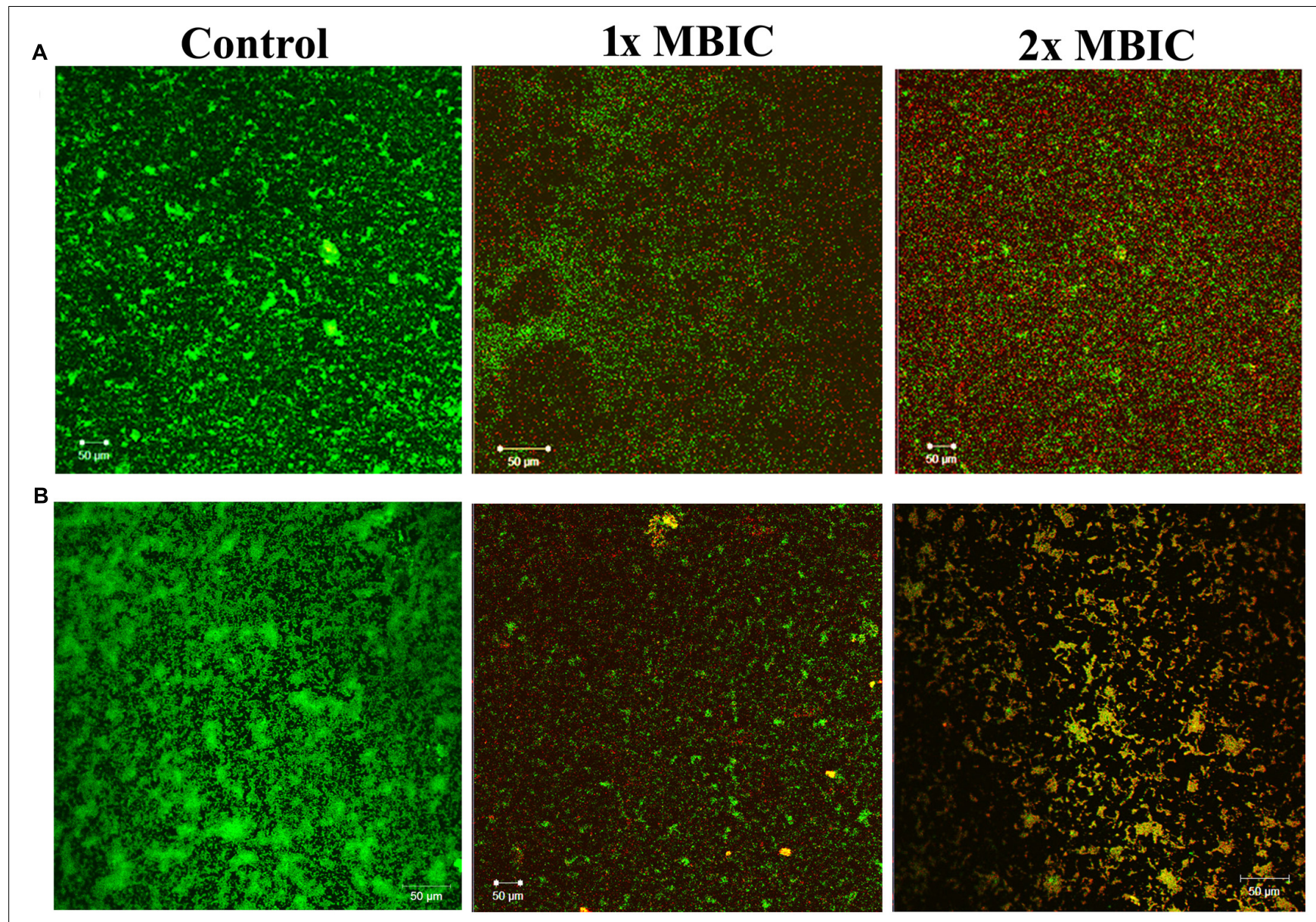

FIGURE 7 | Confocal laser scanning microscopic analysis of the effect of $\mathrm{HMB}$ (at $1 \times \mathrm{MBIC}$ and $2 \times \mathrm{MBIC}$ ) on preformed biofilm (24 h old) of Proteus mirabilis (A) ATCC and (B) Cl using live/dead BacLight bacterial viability staining. Green fluorescence (SYTO9) represents viable cells and red fluorescence (PI) represents dead cells. CLSM, confocal laser scanning microscopy; HMB, 2-hydroxy-4-methoxybenzaldehyde; MBIC, minimum biofilm inhibitory concentration; ATCC, American Type Culture Collection; $\mathrm{Cl}$, clinical isolate; PI, propidium iodide.

Biofilm-associated bacterial cells are encased in an EPS matrix, which is mainly composed of proteins, polysaccharides, and extracellular DNA (eDNA). These EPS components are essential for bacterial cell adherence, proliferation, and resistance development against antibiotics and host defense system (Flemming and Wingender, 2010). Hence, the effect of HMB on EPS of $P$. mirabilis was examined, which revealed the significant EPS inhibitory potential of HMB at its MBIC. Further, FT-IR analysis divulged the EPS inhibitory potential of HMB (MBIC) upon comparison of IR spectral regions of the components (polysaccharides, protein, and eDNA) of EPS samples extracted from control and HMB-treated P. mirabilis culture. The previous report of Issac Abraham et al. (2011) had stated that the antibiofilm efficiency of Capparis spinosa fruit extracts against Gram-negative bacterial pathogens was attributable to its ability to inhibit EPS production. Similarly, in the current study, the reduced biofilm production upon HMB treatment is well corroborated with EPS inhibitory potential of HMB. The preformed robust biofilm exhibits decreased susceptibility to host defenses and antimicrobial treatment (de la Fuente-Núñez et al., 2013). Owing to the biofilm forming ability, elimination of $P$. mirabilis from catheterized urinary tract becomes highly challenging. Hence, the present study also focused on analyzing the effect of HMB on preformed biofilm of $P$. mirabilis. The observation of live/dead staining confirmed the dose-dependent killing efficacy of HMB against biofilmembedded cells.

In addition, motility is a crucial factor for the pathogenicity of P. mirabilis, which helps the organism to colonize on biotic and abiotic surfaces through its characteristic flagellum. The results of present study have demonstrated the anti-swarming and antiswimming efficacy of $\mathrm{HMB}$ against $P$. mirabilis. Additionally, HMB modulated the activity of global gene expression regulators that control the expression of virulence factors and swarming of P. mirabilis. In this respect, Allison et al. (1993) have also reported that the amino acid glutamine acts as a signaling molecule to initiate the swarming differentiation of $P$. mirabilis. Hence, it is speculated that HMB interferes with transduction of glutamine signals possibly to exert the anti-swarming activity. The in-depth analysis of actual mechanism is under progress. 


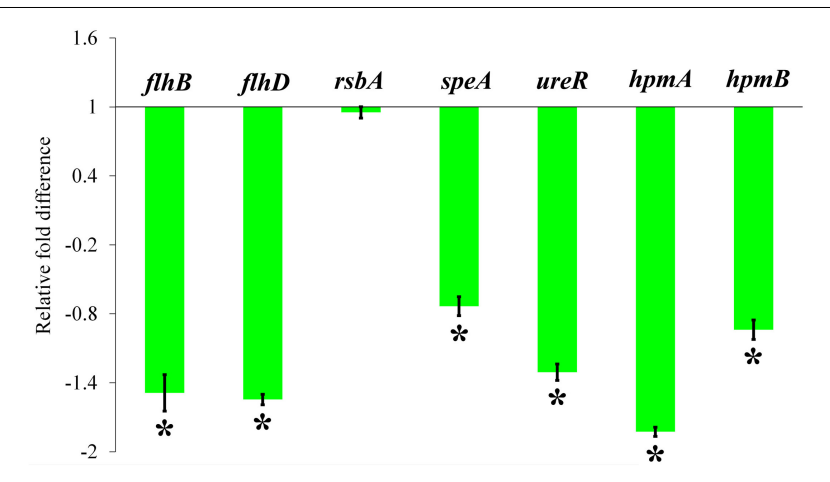

FIGURE 8 | Effect of HMB on virulence genes expression in Proteus mirabilis. Bar chart depicting the relative fold difference in the expression level of virulence genes of $P$. mirabilis in the presence of $\mathrm{HMB}$ at MBIC. Data represent mean values $(n=3) \pm$ standard deviation. * indicates significance at $P<0.005$. HMB, 2-hydroxy-4-methoxybenzaldehyde; MBIC, minimum biofilm inhibitory concentration.

Moreover, the previous report of Foris and Snowden (2017) had stated the association of $P$. mirabilis biofilm formation with its flagella-mediated motility. In this milieu, the antiswimming and anti-swarming abilities exerted by HMB signify the possibilities of $\mathrm{HMB}$ to mitigate the spread of biofilmassociated $P$. mirabilis infections.

Furthermore, the secretion of virulence enzymes, including urease and hemolysin, are most common factors for enriching the pathogenicity of P. mirabilis (Schaffer and Pearson, 2015). Among them, urease is liable for struvite and carbonate apatite crystal production through its urea hydrolysis process. The resulting crystal aggregation remains as the primary factor for kidney stone formation and catheter blockage (Jacobsen and Shirtliff, 2011). Further, in the present study, the crystalline nature of $P$. mirabilis-mediated struvite/apatite precipitates was examined by XRD, FT-IR, and FESEM analyses. The results of these morphological examinations and spectroscopy analyses portrayed the degree of crystallization and chemical compositions of the struvite/apatite precipitates. Furthermore, a significant inhibition of urease production upon HMB (MBIC) treatment was observed (Figures 2A,B). Also, the urease activity of $P$. mirabilis causes encrustations and other serious clinical complications in long-term urethral-catheterized patients via crystalline biofilm production that occurred owing to the impact of alkaline $\mathrm{pH}$ prevailing in urine (Broomfield et al., 2009). Hence, the current study evaluated the crystalline biofilm inhibitory potential of $\mathrm{HMB}$ against $P$. mirabilis. This observation was found to be synchronized with the results of urease inhibitory assay of the present study. These observations led us to envisage that HMB treatment could be able to delay or cease $P$. mirabilis-mediated urinary catheter blockage/encrustation during infections.

On the other hand, hemolysin is a primary cytotoxin, which directly lyses the renal proximal tubular epithelial cells in human (Nagamatsu et al., 2015). Also, the hemolysins were stated to rupture red blood cells often for iron acquisition. Iron is an essential nutrient for microbial proliferation and establishment of infections in host system (Ganz and Nemeth, 2015). HMB was effective in impeding hemolysin production of $P$. mirabilis ATCC and clinical strains (Figure 2A). This might act as a cause for the inability of $P$. mirabilis to survive in the human bloodstream. This prediction was further confirmed through the result of blood survivability assay, wherein the numbers of viable bacterial cells present in HMB-treated blood serum were reduced when compared with those of the untreated control. In addition, HMB treatment reduced the production of siderophore, an iron acquisition molecule. Owing to the HMB's siderophore inhibitory activity, the iron deficiency that occurs in the iron-stressed urinary tract environment is envisaged to affect the $P$. mirabilis colonization and its pathogenicity during infection.

To clarify the plausible molecular mechanism demonstrated by $\mathrm{HMB}$ on $P$. mirabilis, transcriptomic analysis of candidate genes, which directly or indirectly encodes the biofilm and other virulence factors, was examined. The relative expression level of $P$. mirabilis virulence traits upon HMB (MBIC) treatment is shown in Figure 8, wherein the genes $f l h D$ and $f h B$ are responsible for the regulation of flagella-mediated motility of $P$. mirabilis. The swarming behavior of $P$. mirabilis on solid surface is enacted by its flagellum (Patrick and Kearns, 2012). During swarming, the expression of flagellar biosynthesis genes is coordinately regulated in a hierarchy. The flagellar heteromeric complex with master transcriptional regulator $f h D$ regulates the flagellum assembly (like decorating the basal body) by binding to $f h B$ promoter region and leads to the biogenesis of flagellar proteins expression, which in turn harvests the energy for flagellar rotation (Claret and Hughes, 2000; Patrick and Kearns, 2012). In the present study, the qRT-PCR analysis reveals that HMB treatment significantly downregulated the expression level of $f h D$ and flhB genes, which correlated well with the observation of in vitro swarming assay.

And, the gene speA (encodes arginine decarboxylase) is also responsible for $P$. mirabilis swimming and swarming motility, which helps flagellar rotation fueled by proton motive force through utilization of intracellular protons (Armbruster et al., 2014). The gene expression analysis revealed that the expression level of speA gene was considerably downregulated upon HMB treatment (Figure 8). On the contrary, the gene $r s b A$ acts as a negative regulator for $P$. mirabilis swarming migration (Liaw et al., 2001). Wang et al. (2006) had reported that resveratrol inhibited the swarming motility of $P$. mirabilis through an RsbAdependent pathway. Figure $\mathbf{8}$ shows no significant relative fold difference in expression of $r s b A$ gene under $\mathrm{HMB}$ treatment compared with the control. This observation indicates that HMB's anti-swarming activity is not dependent on the RsbA pathway in P. mirabilis.

Further, the expression level of virulence genes upon HMB treatment was evaluated to validate the in vitro bioassay results. Urease, the primary virulence enzyme production in P. mirabilis, was regulated by the transcriptional regulator UreR. This positively activates the expression of urease operon (ure gene cluster), wherein the gene ure $R$ acts as a transcription initiation codon (Dattelbaum et al., 2003). In this concern, the 

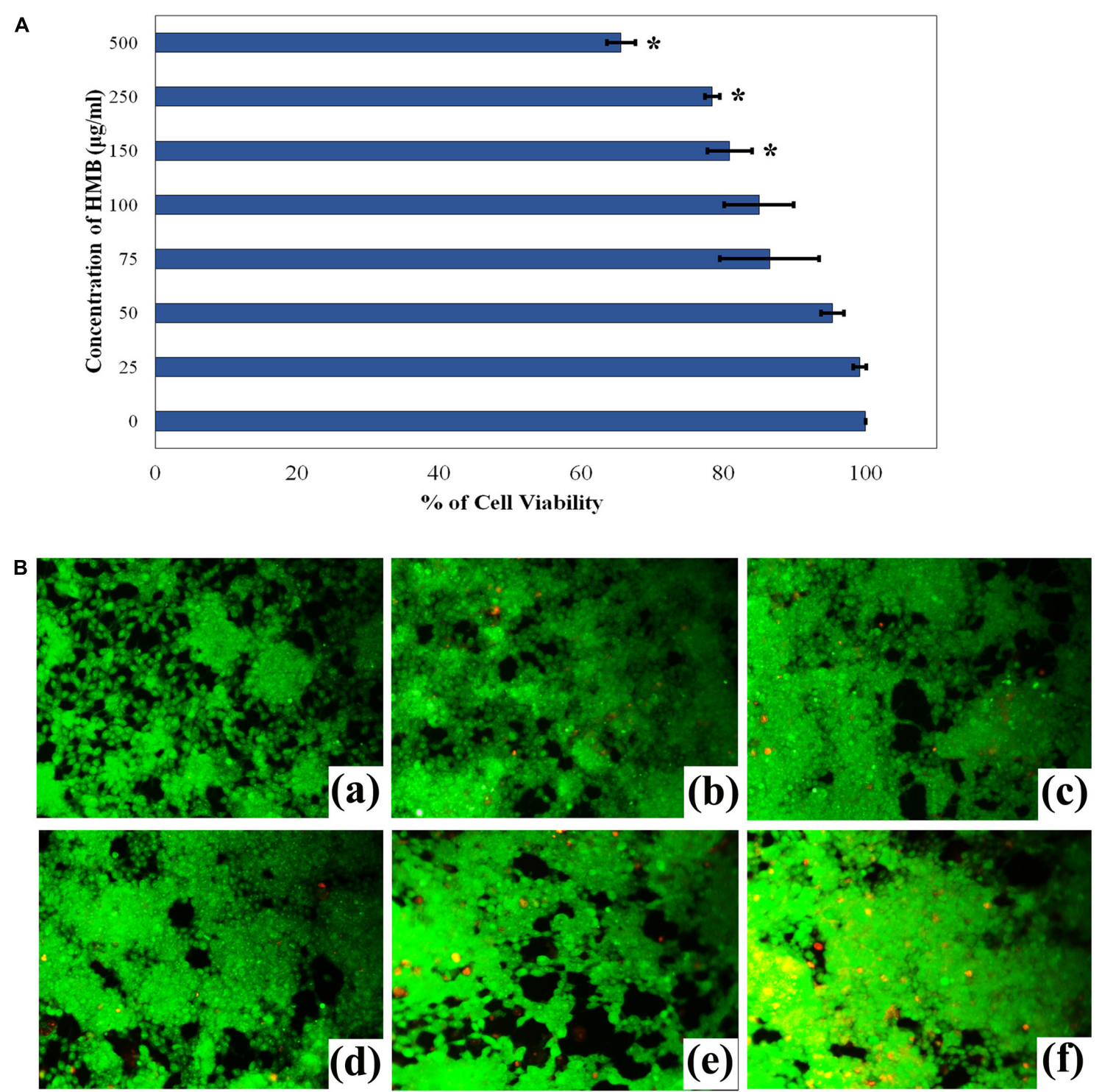

FIGURE 9 | (A) Cytotoxicity assessment of HMB in HEK-293 cells by MTT assay. Data represent mean values $(n=3) \pm$ standard deviation. * indicates significance at $P<0.005$. (B) Fluorescence microscopic images (200x magnifications) of control (a), $25 \mu \mathrm{g} / \mathrm{ml}$ (b), $50 \mu \mathrm{g} / \mathrm{ml}$ (c), $100 \mu \mathrm{g} / \mathrm{ml}$ (d), $250 \mu \mathrm{g} / \mathrm{ml}$, (e) $500 \mu \mathrm{g} / \mathrm{ml}$, and (f) of HMB-treated samples, which clearly depict the non-toxic nature of HMB. Green fluorescence represents viable cell lines, and red fluorescence represents dead cells. HMB, 2-hydroxy-4-methoxybenzaldehyde.

present study reveals that HMB treatment significantly inhibits the urease production through downregulation of ureR gene expression. Likewise, the genes $h p m A$ and $h p m B$ are responsible for P. mirabilis hemolysin production (Cestari et al., 2013). $\mathrm{HpmA}$ hemolysin is activated when its N-terminal peptide is cleaved, resulting in tissue damage; and $\mathrm{HpmB}$ is responsible for HpmA activation and transport. The expression level of $h p m A$ and $h p m B$ genes was also found to be downregulated upon HMB treatment. These observations were found to comply with the urease and hemolysin inhibitory abilities of HMB observed in the in vitro assays.

Moreover, the non-cytotoxic potential of the multifunctional phytocompound HMB was explicated using human kidney cells.
The obtained results showed that HMB did not affect the viability of HEK-293 cells even up to $100 \mu \mathrm{g} / \mathrm{ml}$ of concentration. This observation revealed the innocuous nature of $\mathrm{HMB}$, which concludes that $\mathrm{HMB}$ could be used as a potential therapeutic and preventive agent for $P$. mirabilis infections.

\section{CONCLUSION}

Based on the present study, it could be concluded that HMB treatment efficiently inhibited the pathogenicity of P. mirabilis through downregulation of expression level of virulence genes involved in flagellar motility, biofilm formation, 
EPS production, biosynthesis of urease, and hemolysin enzymes. These results are also reflected in the in vitro virulence assays. Owing to this virulence targeted therapeutic activity, the resistance development in $P$. mirabilis to HMB is presumed to be very scarce. Furthermore, HMB did not exhibit any cytotoxicity against human kidney cell lines. Hence, treatment with HMB as an antibiofilm/antivirulence agent could be a promising therapy to prevent urinary catheter blockage and other biofilm-associated $P$. mirabilis infections.

\section{DATA AVAILABILITY STATEMENT}

All datasets generated for this study are included in the article/Supplementary Material.

\section{ETHICS STATEMENT}

The studies involving human participants were reviewed and approved by the Institutional Ethics Committee, Alagappa University, Karaikudi. Written informed consent for participation was not required for this study in accordance with the national legislation and the institutional requirements.

\section{AUTHOR CONTRIBUTIONS}

$\mathrm{RD}$ designed the study and wrote the manuscript. RD, GA, KN, and $\mathrm{PK}$ performed the experiments. AV provided materials and reagents. SP provided the test pathogen clinical strain. RD and

\section{REFERENCES}

Adeolu, M., Alnajar, S., Naushad, S., and Gupta, R. S. (2016). Genomebased phylogeny and taxonomy of the 'Enterobacteriales': proposal for Enterobacterales ord. nov. divided into the families Enterobacteriaceae, Erwiniaceae fam. nov., Pectobacteriaceae fam. nov., Yersiniaceae fam. nov., Hafniaceae fam. nov., Morganellaceae fam. nov., and Budviciaceae fam. nov. Int. J. Syst. Evol. Microbiol. 66, 5575-5599. doi: 10.1099/ijsem.0.001485

Alexpandi, R., Prasanth, M. I., Ravi, A. V., Balamurugan, K., Durgadevi, R., Srinivasan, R., et al. (2019). Protective effect of neglected plant Diplocyclos palmatus on quorum sensing mediated infection of Serratia marcescens and UV-A induced photoaging in model Caenorhabditis elegans. J. Photochem. Photobiol. B 201:111637. doi: 10.1016/j.jphotobiol.2019.111637

Allison, C., Lai, H. C., Gygi, D., and Hughes, C. (1993). Cell differentiation of Proteus mirabilis is initiated by glutamine, a specific chemo attractant for swarming cells. Mol. Microbiol. 8, 53-60. doi: 10.1111/j.1365-2958.1993. tb01202.x

Armbruster, C. E., Hodges, S. A., Smith, S. N., Alteri, C. J., and Mobley, H. L. (2014). Arginine promotes Proteus mirabilis motility and fitness by contributing to conservation of the proton gradient and proton motive force. Microbiologyopen 3, 630-641. doi: 10.1002/mbo3.194

Armbruster, C. E., Mobley, H. L., and Pearson, M. M. (2018). Pathogenesis of Proteus mirabilis infection. EcoSal Plus 8:ESP-0009-2017. doi: 10.1128/ ecosalplus

Banin, E., Vasil, M. L., and Greenberg, E. P. (2005). Iron and Pseudomonas aeruginosa biofilm formation. Proc. Natl. Acad. Sci. U.S.A 102, 11076-11081.

Belas, R., and Suvanasuthi, R. (2005). The ability of Proteus mirabilis to sense surfaces and regulate virulence gene expression involves FliL, a flagellar basal
RA interpreted the data. All authors approved the final version of the manuscript.

\section{FUNDING}

Financial support rendered to RD through RUSA 2.0 scheme in the form of Ph.D. fellowship [Grant No. F. 24-51/2014-U, Policy (TN Multi-Gen), Department of Education, Government of India] is thankfully acknowledged.

\section{ACKNOWLEDGMENTS}

The authors sincerely thank Ms. T. K. Swetha, Research Scholar, Department of Biotechnology, Alagappa University, Karaikudi, for critically reading the manuscript. The authors also gratefully acknowledge the Department of Biotechnology, Government of India, for providing Bioinformatics Infrastructure Facility [Grant No. BT/BI/25/012/2012(BIF)] at Alagappa University. The authors also acknowledge DST-FIST [Grant No. SR/FST/LSI639/2015(C)], UGC-SAP [Grant No. F.5-1/2018/DRS-II (SAPII)], and DST-PURSE [Grant No. SR/PURSE Phase 2/38(G)] for providing instrumentation facilities.

\section{SUPPLEMENTARY MATERIAL}

The Supplementary Material for this article can be found online at: https://www.frontiersin.org/articles/10.3389/fmicb. 2019.02804/full\#supplementary-material

body protein. J. Bacteriol. 187, 6789-6803. doi: 10.1128/jb.187.19.6789-6803. 2005

Broomfield, R. J., Morgan, S. D., Khan, A., and Stickler, D. J. (2009). Crystalline bacterial biofilm formation on urinary catheters by urease-producing urinary tract pathogens: a simple method of control. J. Med. Microbiol. 58, 1367-1375. doi: 10.1099/jmm.0.012419-0

Cestari, S. E., Ludovico, M. S., Martins, F. H., da Rocha, S. P. D., Elias, W. P., and Pelayo, J. S. (2013). Molecular detection of HpmA and HlyA hemolysin of uropathogenic Proteus mirabilis. Curr. Microbiol. 67, 703-707. doi: 10.1007/ s00284-013-0423-5

Chauhan, C. K., and Joshi, M. J. (2013). In vitro crystallization, characterization and growth-inhibition study of urinary type struvite crystals. J. Cryst. Growth 362, 330-337. doi: 10.1016/j.jcrysgro.2011.11.008

Cheng, M. (2016). Sharing economy: a review and agenda for future research. Int. J. Hosp. Manag. 57, 60-70. doi: 10.1016/j.ijhm.2016.06.003

Claret, L., and Hughes, C. (2000). Functions of the subunits in the FlhD2C2 transcriptional master regulator of bacterial flagellum biogenesis and swarming. J. Mol. Biol. 303, 467-478. doi: 10.1006/jmbi.2000.4149

Clinical and Laboratory Standards Institute [CLSI], (2016). Performance Standards for Antimicrobial Susceptibility Testing; Twenty-Fifth Informational Suppl. M100-S26. Wayne, PA: CLSI.

Dattelbaum, J. D., Lockatell, C. V., Johnson, D. E., and Mobley, H. L. (2003). UreR, the transcriptional activator of the Proteus mirabilis urease gene cluster, is required for urease activity and virulence in experimental urinary tract infections. Infect. Immun. 71, 1026-1030. doi: 10.1128/iai.71.2.1026-1030. 2003

de la Fuente-Núñez, C., Reffuveille, F., Fernández, L., and Hancock, R. E. (2013). Bacterial biofilm development as a multicellular adaptation: antibiotic 
resistance and new therapeutic strategies. Curr. Opin. Microbiol. 16, 580-589. doi: 10.1016/j.mib.2013.06.013

Durgadevi, R., Ravi, A. V., Alexpandi, R., Swetha, T. K., Abirami, G., Vishnu, S., et al. (2019). Virulence targeted inhibitory effect of linalool against the exclusive uropathogen Proteus mirabilis. Biofouling 35, 508-525. doi: 10.1080/08927014. 2019.1619704

Flemming, H. C., and Wingender, J. (2010). The biofilm matrix. Nat. Rev. Microbiol. 8, 623-633. doi: 10.1038/nrmicro2415

Flores-Mireles, A. L., Walker, J. N., Caparon, M., and Hultgren, S. J. (2015). Urinary tract infections: epidemiology, mechanisms of infection and treatment options. Nat. Rev. Microbiol. 13, 269-284. doi: 10.1038/nrmicro3432

Foris, L. A., and Snowden, J. (2017). Proteus Mirabilis Infections. In StatPearls. StatPearls Publishing. Available at: http://www.ncbi.nlm.nih.gov/pubmed/ 28723046 (accessed 19 November 2017).

Foxman, B., and Brown, P. (2003). Epidemiology of urinary tract infections: transmission and risk factors, incidence, and costs. Infect. Dis. Clin. N. Am. 17, 227-241.

Fraser, G. M., Claret, L., Furness, R., Gupta, S., and Hughes, C. (2002). Swarmingcoupled expression of the Proteus mirabilis hpmBA haemolysin operona. Microbiology 148, 2191-2201. doi: 10.1099/00221287-148-7-2191

Ganz, T., and Nemeth, E. (2015). Iron homeostasis in host defence and inflammation. Nat. Rev. Immunol. 15, 500-510. doi: 10.1038/nri 3863

Hamilton, A. L., Kamm, M. A., Ng, S. C., and Morrison, M. (2018). Proteus spp. as putative gastrointestinal pathogens. Clin. Microbiol. Rev. 31, e85-e17. doi: 10.1128/CMR.00085-17

Harjai, K., Kumar, R., and Singh, S. (2010). Garlic blocks quorum sensing and attenuates the virulence of Pseudomonas aeruginosa. FEMS Immunol. Med. Microbiol. 58, 161-168. doi: 10.1111/j.1574-695X.2009.00614.x

Himpsl, S. D., Pearson, M. M., Arewång, C. J., Nusca, T. D., Sherman, D. H., and Mobley, H. L. (2010). Proteobactin and a yersiniabactin-related siderophore mediate iron acquisition in Proteus mirabilis. Mol. Microbiol. 78, 138-157. doi: 10.1111/j.1365-2958.2010.07317.x

Hola, V., Peroutkova, T., and Ruzicka, F. (2012). Virulence factors in Proteus bacteria from biofilm communities of catheter-associated urinary tract infections. FEMS Immunol. Med. Microbiol. 65, 343-349. doi: 10.1111/j.1574695X.2012.00976.x

Holling, N., Lednor, D., Tsang, S., Bissell, A., Campbell, L., Nzakizwanayo, J., et al. (2014). Elucidating the genetic basis of crystalline biofilm formation in Proteus mirabilis. Infect. Immun. 82, 1616-1626. doi: 10.1128/IAI.01 652-13

Issac Abraham, S. V. P. I., Palani, A., Ramaswamy, B. R., Shunmugiah, K. P., and Arumugam, V. R. (2011). Antiquorum sensing and antibiofilm potential of Capparis spinosa. Arch. Med. Res. 42, 658-668. doi: 10.1016/j.arcmed.2011.12. 002

Jacobsen, S. M., and Shirtliff, M. E. (2011). Proteus mirabilis biofilms and catheterassociated urinary tract infections. Virulence 2, 460-465. doi: 10.4161/viru.2.5. 17783

Jacobsen, S. Á., Stickler, D. J., Mobley, H. L. T., and Shirtliff, M. E. (2008). Complicated catheter-associated urinary tract infections due to Escherichia coli and Proteus mirabilis. Clin. Microbiol. Rev. 21, 26-59. doi: 10.1128/CMR.0001907

Jiang, Q., Chen, J., Yang, C., Yin, Y., and Yao, K. (2019). Quorum sensing: a prospective therapeutic target for bacterial diseases. Biomed. Res. Int. 2019:2015978. doi: 10.1155/2019/2015978

Jones, B. V., Mahenthiralingam, E., Sabbuba, N. A., and Stickler, D. J. (2005). Role of swarming in the formation of crystalline Proteus mirabilis biofilms on urinary catheters. J. Med. Microbiol. 54, 807-813. doi: 10.1099/jmm.0. 46123-0

Kannappan, A., Srinivasan, R., Nivetha, A., Annapoorani, A., Pandian, S. K., and Ravi, A. V. (2019). Anti-virulence potential of 2-hydroxy-4methoxybenzaldehyde against methicillin-resistant Staphylococcus aureus and its clinical isolates. Appl. Microbiol. Biotechnol. 103, 6747-6758. doi: 10.1007/ s00253-019-09941-6

Liaw, S. J., Lai, H. C., Ho, S. W., Luh, K. T., and Wang, W. B. (2000). Inhibition of virulence factor expression and swarming differentiation in Proteus mirabilis by p-nitrophenylglycerol. J. Med. Microbiol. 49, 725-731. doi: 10.1099/00221317-49-8-725
Liaw, S. J., Lai, H. C., Ho, S. W., Luh, K. T., and Wang, W. B. (2001). Characterisation of p-nitrophenylglycerol-resistant Proteus mirabilis superswarming mutants. J. Med. Microbiol. 50, 1039-1048. doi: 10.1099/0022-131750-12-1039

Louden, B. C., Haarmann, D., and Lynne, A. M. (2011). Use of blue agar CAS assay for siderophore detection. J. Microbial. Biol. Educ. 12, 51-53. doi: 10.1128/jmbe. v12i1.249

Martínez, O. F., Cardoso, M. H., Ribeiro, S. M., and Franco, O. L. (2019). Recent advances in anti-virulence therapeutic strategies with a focus on dismantling bacterial membrane microdomains, toxin neutralization, quorumsensing interference and biofilm inhibition. Front. Cell. Infect. Microbiol. 9:74. doi: 10.3389/fcimb.2019.00074

Morgenstein, R. M., Szostek, B., and Rather, P. N. (2010). Regulation of gene expression during swarmer cell differentiation in Proteus mirabilis. FEMS Microbiol. Rev. 34, 753-763. doi: 10.1111/j.1574-6976.2010.00229.x

Musthafa, K. S., Ravi, A. V., Annapoorani, A., Packiavathy, I. S. V., and Pandian, S. K. (2010). Evaluation of anti-quorum-sensing activity of edible plants and fruits through inhibition of the $\mathrm{N}$-acyl-homoserine lactone system in Chromobacterium violaceum and Pseudomonas aeruginosa. Chemotherapy 56, 333-339. doi: 10.1159/000320185

Nagamatsu, K., Hannan, T. J., Guest, R. L., Kostakioti, M., Hadjifrangiskou, M., Binkley, J., et al. (2015). Dysregulation of Escherichia coli $\alpha$-hemolysin expression alters the course of acute and persistent urinary tract infection. Proc. Natl. Acad. Sci. U.S.A. 112, E871-E880. doi: 10.1073/pnas.1500374112

Patrick, J. E., and Kearns, D. B. (2012). Swarming motility and the control of master regulators of flagellar biosynthesis. Mol. Microbiol. 83, 14-23. doi: 10.1111/j. 1365-2958.2011.07917.x

Possenti, E., Conti, C., Gatta, G., Realini, M., and Colombo, C. (2019). Diammonium hydrogenphosphate treatment on dolostone: the role of $\mathrm{Mg}$ in the crystallization process. Coatings 9:169. doi: 10.3390/coatings9030169

Prywer, J., Kozanecki, M., Mielniczek-Brzóska, E., and Torzewska, A. (2018). Solid phases precipitating in artificial urine in the absence and presence of bacteria Proteus mirabilis -a contribution to the understanding of infectious urinary stone formation. Crystals 8:164. doi: 10.3390/cryst8040164

Ramanathan, S., Ravindran, D., Arunachalam, K., and Arumugam, V. R. (2018). Inhibition of quorum sensing-dependent biofilm and virulence genes expression in environmental pathogen Serratia marcescens by petroselinic acid. Antonie Van Leeuwenhoek 111, 501-515. doi: 10.1007/s10482-017-0971-y

Raorane, C. J., Lee, J. H., Kim, Y. G., Rajasekharan, S. K., García-Contreras, R., and Lee, J. (2019). Antibiofilm and antivirulence efficacies of flavonoids and curcumin against Acinetobacter baumannii. Front. Microbiol. 10:990. doi: 10. 3389/fmicb.2019.00990

Ravindran, D., Ramanathan, S., Arunachalam, K., Jeyaraj, G. P., Shunmugiah, K. P., and Arumugam, V. R. (2018). Phytosynthesized silver nanoparticles as antiquorum sensing and antibiofilm agent against the nosocomial pathogen Serratia marcescens: an in vitro study. J. Appl. Microbiol. 124, 1425-1440. doi: 10.1111/jam. 13728

Sabbuba, N. A., Mahenthiralingam, E., and Stickler, D. J. (2003). Molecular epidemiology of Proteus mirabilis infections of the catheterized urinary tract. J. Clin. Microbiol. 41, 4961-4965. doi: 10.1128/jcm.41.11.4961-4965.2003

Schaffer, J. N., and Pearson, M. M. (2015). Proteus mirabilis and urinary tract infections. Microbiol. Spectr. 3:UTI-0017-2013. doi: 10.1128/microbiolspec. UTI-0017-2013

Singh, U., Akhtar, S., Mishra, A., and Sarkar, D. (2011). A novel screening method based on menadione mediated rapid reduction of tetrazolium salt for testing of anti-mycobacterial agents. J. Microbiol. Methods 84, 202-207. doi: 10.1016/j. mimet.2010.11.013

Sivasankar, C., Maruthupandiyan, S., Balamurugan, K., James, P. B., Krishnan, V., and Pandian, S. K. (2016). A combination of ellagic acid and tetracycline inhibits biofilm formation and the associated virulence of Propionibacterium acnes in vitro and in vivo. Biofouling 32,397-410. doi: 10.1080/08927014.2016. 1148141

Soto, S. M. (2014). Importance of biofilms in urinary tract infections: new therapeutic approaches. Adv. Biol. Res. 2014, 1-13. doi: 10.1155/2014/543974

Srikanta, B. M., Nayaka, M. A. H., and Dharmesh, S. M. (2011). Inhibition of helicobacter pylori growth and its cytotoxicity by 2-hydroxy 4-methoxy benzaldehyde of decalepis hamiltonii (wight \& arn); a new functional attribute. Biochimie 93, 678-688. doi: 10.1016/j.biochi.2010.12.009 
Srinivasan, R., Vigneshwari, L., Rajavel, T., Durgadevi, R., Kannappan, A., Balamurugan, K., et al. (2018). Biogenic synthesis of silver nanoparticles using Piper betle aqueous extract and evaluation of its anti-quorum sensing and antibiofilm potential against uropathogens with cytotoxic effects: an in vitro and in vivo approach. Environ. Sci. Pollut. Res. 25, 10538-10554. doi: 10.1007/ s11356-017-1049-0

Stamm, W. E., and Norrby, S. R. (2001). Urinary tract infections: disease panorama and challenges. J. Infect. Dis. 183(Suppl. 1), S1-S4.

Stickler, D. J., and Jones, G. L. (2008). Reduced susceptibility of Proteus mirabilis to triclosan. Antimicrob. Agents Chemother. 52, 991-994. doi: 10.1128/AAC. 01094-07

Stockert, J. C., Horobin, R. W., Colombo, L. L., and Blazquez-Castro, A. (2018). Tetrazolium salts and formazan products in cell biology: viability assessment, fluorescence imaging, and labeling perspectives. Acta Histochem. 120, 159-167. doi: 10.1016/j.acthis.2018.02.005

Subramenium, G. A., Viszwapriya, D., Iyer, P. M., Balamurugan, K., and Pandian, S. K. (2015). $\operatorname{cov} R$ mediated antibiofilm activity of 3-furancarboxaldehyde increases the virulence of group A streptococcus. PLoS One 10:e0127210. doi: 10.1371/journal.pone. 0127210

Torzewska, A., and Rozalski, A. (2014). Inhibition of crystallization caused by Proteus mirabilis during the development of infectious urolithiasis by various phenolic substances. Microbiol. Res. 169, 579-584. doi: 10.1016/j.micres.2013. 09.020

Totsika, M. (2017). Disarming pathogens: benefits and challenges of antimicrobials that target bacterial virulence instead of growth and viability. Future Med. Chem. 9, 267-269. doi: 10.4155/fmc-2016-0227

Trautner, B. W. (2010). Management of catheter-associated urinary tract infection (CAUTI). Curr. Opin. Infect. Dis. 23, 76-82.
Viszwapriya, D., Subramenium, G. A., Prithika, U., Balamurugan, K., and Pandian, S. K. (2016). Betulin inhibits virulence and biofilm of Streptococcus pyogenes by suppressing ropB core regulon, sagA and dltA. FEMS Pathog. Dis. 74:ftw088.

Wang, J., Liu, H., Zhao, J., Gao, H., Zhou, L., Liu, Z., et al. (2010). Antimicrobial and antioxidant activities of the root bark essential oil of Periploca sepium and its main component 2-hydroxy-4-methoxybenzaldehyde. Molecules 15, 5807-5817. doi: 10.3390/molecules 15085807

Wang, W. B., Lai, H. C., Hsueh, P. R., Chiou, R. Y. Y., Lin, S. B., and Liaw, S. J. (2006). Inhibition of swarming and virulence factor expression in Proteus mirabilis by resveratrol. J. Med. Microbiol. 55, 1313-1321. doi: 10.1099/jmm.0. 46661-0

Yang, Y. X., Xu, Z. H., Zhang, Y. Q., Tian, J., Weng, L. X., and Wang, L. H. (2012). A new quorum-sensing inhibitor attenuates virulence and decreases antibiotic resistance in Pseudomonas aeruginosa. J. Microbiol. 50, 987-993. doi: $10.1007 /$ s12275-012-2149-7

Conflict of Interest: The authors declare that the research was conducted in the absence of any commercial or financial relationships that could be construed as a potential conflict of interest.

Copyright (c) 2019 Durgadevi, Abirami, Alexpandi, Nandhini, Kumar, Prakash and Veera Ravi. This is an open-access article distributed under the terms of the Creative Commons Attribution License (CC BY). The use, distribution or reproduction in other forums is permitted, provided the original author(s) and the copyright owner(s) are credited and that the original publication in this journal is cited, in accordance with accepted academic practice. No use, distribution or reproduction is permitted which does not comply with these terms. 